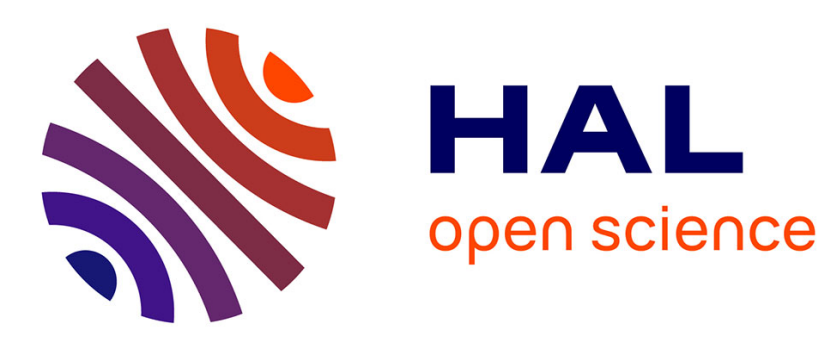

\title{
Atomic Layer Deposition to Materials for Gas Sensing Applications
}

\author{
Catherine Marichy, Nicola Pinna
}

\section{To cite this version:}

Catherine Marichy, Nicola Pinna. Atomic Layer Deposition to Materials for Gas Sensing Applications. Advanced Materials Interfaces, 2016, 3 (21), pp.1600335. 10.1002/admi.201600335 . hal-02106437

\section{HAL Id: hal-02106437 \\ https://hal.science/hal-02106437}

Submitted on 23 Jun 2020

HAL is a multi-disciplinary open access archive for the deposit and dissemination of scientific research documents, whether they are published or not. The documents may come from teaching and research institutions in France or abroad, or from public or private research centers.
L'archive ouverte pluridisciplinaire HAL, est destinée au dépôt et à la diffusion de documents scientifiques de niveau recherche, publiés ou non, émanant des établissements d'enseignement et de recherche français ou étrangers, des laboratoires publics ou privés. 


\title{
Atomic layer deposition to materials for gas sensing applications
}

\author{
Catherine Marichy ${ }^{1, *}$ and Nicola Pinna, ${ }^{2, *}$ \\ 1 - Laboratoire des Multimatériaux et Interfaces, UMR 5615, Université Claude Bernard Lyon 1/CNRS, \\ Villeurbanne, France. \\ 2 - Institut für Chemie, Humboldt-Universität zu Berlin, Brook-Taylor-Str. 2, 12489 Berlin, Germany.
}

\begin{abstract}
Atomic layer deposition is a thin film deposition technique based on self-terminated surface reactions. Contrarily to most of the thin film deposition techniques, it is not a line of sight deposition technique due to the sequential introduction of the gaseous precursors and because the reactants can only react with surface species. The precursors can thus diffuse into porous structures and the conformal coating of high aspect ratio structures can be achieved. Because of these peculiarities atomic layer deposition is an attractive technique for fabricating materials to be applied in resistive gas sensors. The present article focuses on materials for resistive gas sensor devices in which the sensing material is elaborated using atomic layer deposition, in at least one step of the fabrication. It will be shown that atomic layer deposition has proven to be well-suited for the elaboration of compact thin films, nanostructures and heterostructures to be applied for the detection of a variety of analytes such as toxic compounds, pollutants, explosives, etc. The chemical and physical properties of the sensing layers will be discussed in parallel to the gas sensing mechanisms in an attempt to develop clear structure-property correlations.
\end{abstract}




\section{Bibliography}

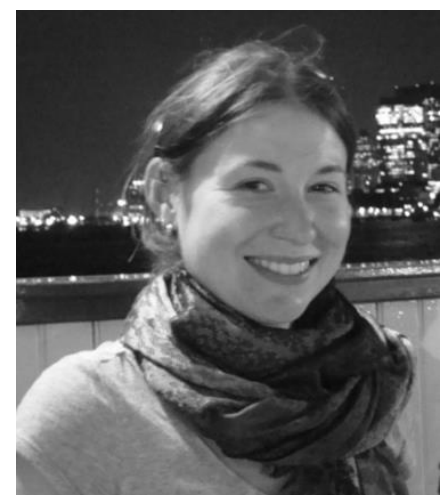

Catherine Marichy received her degree in Inorganic Chemistry in 2008 from the University Claude Bernard, Lyon 1 (France). In 2008, she joined the group of N. Pinna at the Department of Chemistry and CICECO of the University of Aveiro (Portugal) where she received her Ph.D. in 2012. Then she moved to the University of Fribourg (Switzerland) as post graduate assistant at the soft mater and photonics group of the physic department. Since 2013, she is a CNRS researcher at the "Laboratoire des Multimatériaux et Interface", at the University of Lyon. Her research focuses on the elaboration of heterostructures by atomic layer deposition, their characterization and the investigation of their physical properties.

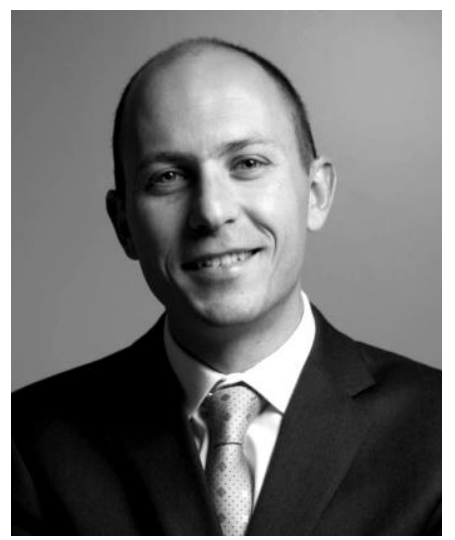

Nicola Pinna studied physical chemistry at the Université Pierre et Marie Curie (Paris). He received his Ph.D. in 2001, and in 2002, he moved to the Fritz Haber Institute of the Max Planck Society (Berlin). In 2003, he joined the Max Planck Institute of Colloids and Interfaces (Potsdam). In 2005, he moved to the Martin Luther University, Halle-Wittenberg, as an Assistant Professor of Inorganic Chemistry. From March 2006 to June 2012 he was researcher at the Department of Chemistry and CICECO of the University of Aveiro and from September 2009 to June 2012 he was also Assistant Professor at the School of Chemical and Biological Engineering of the Seoul National University. In July 2012 he joined the Department of Chemistry of the Humboldt University in Berlin. His research activity is focused on the development of novel routes to nanostructured materials, their characterization, and the study of their physical properties. 


\section{Introduction}

Gas sensors are among the most important technologies constantly presented in all the aspects of our lives. Gas sensors are applied for the detection of pollutants, toxic compounds, explosives, for monitoring the air quality, industrial processes and for domestic safety, for example. ${ }^{[1]}$

Among the various types of gas sensors, resistive or conductimetric gas sensors are attractive because they are cheap, simple to fabricate and to operate. They are composed of a sensitive layer deposited on a substrate provided with electrodes and a heater which is separated from the electrode and the sensing layer by an insulator. The sensing layer is in most of the cases fabricated by drop casting of a suspension of the sensing material onto the supported electrodes. Such a device is generally operated in air at temperatures ranging from 200 and $400{ }^{\circ} \mathrm{C}$. At these temperatures in the presence of oxygen, humidity and other interfering gases such as carbon dioxide various species are present at the surface and can influence the electrical properties of the sensing layer by competing with the absorption of the analyte. In order to gain the desired chemical information, changes in the resistance/conductance of the device are recorded as a function of time. If we consider a simplistic description of the conduction mechanism depending on the geometry of the sensing layer two limit cases have to be expected. For a compact sensing layer, the change in band bending at the material/electrode interface upon absorption of an analyte is the main mechanism leading to changes in the resistance that are measured. Whereas, for polycrystalline porous sensing layers, the potential barriers appearing at the grain-grain depend on the absorbed analyte, and the concentration of the electrons that can travel between the two electrodes (for an n-type semiconductor) is modulated by the potential height.

The sensor sensitivity is generally defined as $S=R_{a} / R_{g}$ or $S=R_{g} / R_{a}$ where $R_{a}$ and $R_{g}$ are resistance in air and in the presence of the gas analyte, respectively. For porous polycrystalline films the sensitivity is strongly dependent on the radius of the semiconductive crystallites. When the radius is much larger than the thickness of the electron depletion layer only the surface of the crystallite is depleted in charge carriers. On the other hand, when the radius is smaller or equal to the electron depletion layer the entire grain is depleted, and the sensitivity is maximized. ${ }^{[2]}$

It is not the objective of this article to enter into the details of the complex surface reaction and transduction mechanisms, and how different surface and gaseous species can interfere with each other. These are very complex questions that are at the base of surface science and cannot be answered by simply conductometric experiments, one can typically find in articles, but by additional spectroscopic studies during the sensors operation. Unfortunately, most of the surface science techniques available have to be applied in conditions away from the normal operation of the sensors, i.e. in UHV or low temperature. For an interesting and deeper discussion of these problematics we refer the reader to dedicated articles on the subject. ${ }^{[1 a, 3]}$ The main objective of this article is to highlight the peculiarity of atomic layer deposition (ALD) for the fabrication of the sensing layer in resistive sensors.

ALD is a thin film deposition technique based on self-terminated surface reactions. The principle is similar to chemical vapor deposition (CVD), but contrary to CVD the reactants never meet in the reaction chamber and react only with surface species forming at most one monolayer per cycle. One ALD cycle of 
a typical process for the deposition of a binary compound consists in i) the introduction of a precursor $\mathrm{A}$ reacting with active surface species, ii) a purge for eliminating the unreacted precursor $A$ and reaction products from the deposition chamber, iii) the introduction of a precursor $B$ reacting with the surface species created during (i), and iv) finally a second purge for eliminating the unreacted precursor $B$ and by-products. Such a cycle is repeated as many times as required for reaching the desired thin film thickness. ALD has been applied to the deposition of a large variety of material classes ranging from pure elements to chalcogenides, nitrides, carbides, etc. ${ }^{[4]}$

Due to the sequential introduction of the precursors separated by long purges an ALD cycle can take from few seconds to several minutes, depending on the precursor characteristics, chamber design and morphology of the substrate to be coated. Therefore, ALD is not suitable for the growth of thick films. On the other hand, ALD is not a line of sight deposition technique such as physical vapor deposition. Therefore, because the precursors can only react with surface species and can diffuse into porous structures, ALD has become the technique of choice for coating high aspect ratio and nanostructured substrates. A typical example of this success is the adoption of ALD from the microelectronic industry for the fabrication of high aspect ratio MIM DRAM capacitors. ${ }^{[5]}$ Since many years ALD has already been used for the modification and the fabrication of complex structures. ${ }^{[6]}$ Because of its peculiarities ALD is also an attractive technique for fabricating thin films and nanostructures to be applied as active materials in resistive gas sensors. For example, by precisely controlling the thickness of the active thin film the sensitivity of the sensor can be maximized when the film thickness approaches the Debye length of the semiconductor deposited. Since, the Debye length, of the materials considered in resistive gas sensors, is in the order of few $\mathrm{nm}$, only very few deposition techniques can be considered when such a level of thickness control is required. Moreover, since ALD permits the conformal coating of high aspect ratio structure, it can be used for the fabrication of chemically and morphologically complex and porous nanostructures with an unprecedented control of the thickness of the components. Such peculiarities not only permit to optimize the properties of the sensors fabricated such as operation temperature, sensitivity, selectivity and response time, but also to verify fundamental theories and to develop structure-properties relationships.

In this article, we aim at summarizing the most significant progresses related to gas sensors based on thin films, nanostructures and heterostructures in which at least one step of the fabrication process is carried out using ALD. We will discuss the nanostructure properties in parallel to the sensing mechanisms in order to try to develop clear structure-property correlations.

\section{Thin films as gas sensors}

Compact sensing layer based on thin films deposited by ALD (Table 1) are interesting because their fabrication is compatible with the one of integrated circuits and therefore low production costs are expected together with the possibility for miniaturization. An improvement of the sensitivity, response and recovery times, and energy consumption can be expected due to the short gas diffusion paths and low resistance of compact films. 
$\mathrm{SnO}_{2}$ is the material of choice for resistive gas sensors and was also the first material deposited by ALD for gas detection. Rosental et al. reported the deposition of $\mathrm{SnO}_{2}$ starting from tin halides and either water, ${ }^{[7]}$ oxygen or hydrogen peroxide ${ }^{[8]}$ as oxygen sources. In the first report, they showed that amorphous $\mathrm{SnO}_{2}$ films respond to carbon monoxide at operating temperatures ranging from 160 to 320 ${ }^{\circ} \mathrm{C}$. The same authors also showed that the sensitivity is strongly dependent on the ALD process. For example, films deposited from metal halides display different sensitivities due to the different final concentration of oxygen vacancies depending on the tin halide precursor used. The growth of $\mathrm{SnO}_{2}$ on sapphire carried out from $\mathrm{Snl}_{4}$ and oxygen at $600{ }^{\circ} \mathrm{C}$ is epitaxial. The film displays a higher conductivity due to the high concentration of oxygen vacancies and a higher sensitivity to $\mathrm{CO}$ compared to films grown from $\mathrm{SnCl}_{4}{ }^{[8]}$ Polycrystalline films of $\mathrm{SnO}_{2}$ deposited from $\mathrm{SnCl}_{4}$ and water at $500{ }^{\circ} \mathrm{C}$ showed also to be sensitive to volatile organic compounds such as ethanol, acetone and acrylonitrile. ${ }^{[9]} \mathrm{A}$ plasma enhanced ALD process was developed starting from dibutyl tin diacetate and oxygen plasma. The $\mathrm{SnO}_{2}$ films are polycrystalline and the crystallite size and surface morphology could be simply controlled by the deposition temperature or post-deposition annealing. ${ }^{[10]}$ It was demonstrated that an increase of surface roughness led to an increase of the sensitivity of the sensors due to a higher specific surface area and therefore density of absorption sites.

The importance of the film thickness was highlighted in the work of Du and George on the detection of $\mathrm{CO}$ by $\mathrm{SnO}_{2}$ films deposited directly onto a simple substrate provided with two electrodes in the front and a heater on the back side (Figure 1a). ${ }^{[11]} \mathrm{A}$ maximum of the sensitivity is observed for a thickness of $2.5 \mathrm{~nm}$ (Figure 1b), which corresponds to the Debye length $\left(\mathrm{L}_{\mathrm{d}}\right)$ of $\mathrm{SnO}_{2}{ }^{[12]}$ Similarly a maximum of sensitivity towards $\mathrm{NO}_{2}$ was observed for $3 \mathrm{~nm}$-thick $\mathrm{SnO}_{2}$ coating on CNTs, while thicker coating displayed lower sensitivity (vide infra). ${ }^{[13]}$ Due to the very precise thickness control it provides, ALD appears to be the technique of choice for the deposition of few nm-thick films for sensing applications. As a further example, the electric and gas sensing properties of $\mathrm{SnO}_{2}$ ALD granular films as a function of the thickness (from 7 to $140 \mathrm{~nm}$ ) and post-deposition annealing treatments has been studied by Natarajan and Cameron. ${ }^{[14]}$ Du and George also used the $\mathrm{SnO}_{2}$ ALD films in an attempt to discriminate between the ionosorption and the oxygen vacancy mechanisms involved in CO sensing. ${ }^{[15]}$ The ionosoprtion model postulated that $\mathrm{O}_{2}$ can adsorb on the surface as ion species by trapping a conduction electron. Upon CO exposure, the reducing gas reacts with the surface oxygen species, releasing the captured electrons. On the other hand, the oxygen vacancy mechanism is based on the hypothesis that a reducing gas reacts with surface oxygen atoms of the metal oxide, leaving a oxygen vacancy which is refilled by $\mathrm{O}_{2}$ from the air. By in situ $\mathrm{FTIR}$ on $\mathrm{SiO}_{2}$ supported $\mathrm{SnO}_{2}$ films thinner than the Debye length (i.e. $1 \mathrm{~nm}$ ), the concentration of the gas species involved in CO sensing could be monitored. The results suggested that $\mathrm{CO}$ can form oxygen vacancies at the surface of the $\mathrm{SnO}_{2}$ film and $\mathrm{CO}$ can be detected also in the absence of $\mathrm{O}_{2}$, however $\mathrm{O}_{2}$ is needed to refill the oxygen vacancies after removal of $\mathrm{CO}$, so to obtain a reversible gas sensor. Although all the results are in agreement with the oxygen vacancy model the ionosorption model could not be ruled out. Additional experiments on ultrathin $\mathrm{SnO}_{2}$ films deposited on a substrate not absorbing between 800 and $1300 \mathrm{~cm}^{-1}$ would be needed to rule out the formation of ionosorbed oxygen species such as $\mathrm{O}_{2}{ }^{-}$and $\mathrm{O}^{-}$surface species. Rosental et al. grew epitaxial rutile-type $\mathrm{SnO}_{2}$ and heterostructures $\mathrm{TiO}_{2} / \mathrm{SnO}_{2}$ onto $r$-cut $\alpha$-alumina and 
demonstrated that single crystals thin films of metal oxide semiconductors exhibit good responses towards reducing gases (i.e. $\mathrm{H}_{2}, \mathrm{CO}$ and $\mathrm{CH}_{4}$ ). ${ }^{[16]}$

On top of $\mathrm{SnO}_{2}$ additional metal oxides such as $\mathrm{ZnO}$ for the detection of $\mathrm{O}_{2}, \mathrm{CO}$ and ethanol, ${ }^{[17]} \mathrm{TiO}_{2}$ for $\mathrm{H}_{2}{ }^{[18]}$ and $\mathrm{La}_{2} \mathrm{O}_{3}$ for $\mathrm{CO}_{2}{ }^{[19]}$ at room temperature have been reported. For example, it was demonstrated that the concentration of charge carriers of $\mathrm{ZnO}$ films depends on the ALD process and the subsequent thermal treatment. An oxygen plasma assisted ALD process lead to a higher concentration of charge carriers, so to a lower resistivity of the film compared to a thermal process using water as oxygen source. ${ }^{[17 c]}$ The epitaxial growth of $\mathrm{TiO}_{2}$ brookite on (110) yttria-stabilized zirconia was recently reported by Kim et al. Such a structure permits to detect $\mathrm{H}_{2}$ at low temperature with good selectively especially at $150{ }^{\circ} \mathrm{C}$ (Figure 1c,d). ${ }^{[18 a]}$ Finally, 20nm perovskite $\mathrm{SrTiO}_{3}$ ALD films deposited from $\mathrm{Sr}(\mathrm{thd})_{2}$ and $\mathrm{Ti}(\mathrm{OiPr})_{4}$ at $300{ }^{\circ} \mathrm{C}$ using ozone and water as oxygen source for the metal $\beta$-diketonate and the metal alkoxide respectively. ${ }^{[20]}$ Although highly resistive, the perovskite film exhibited a high sensitivity to $\mathrm{O}_{2}$ at room temperature.

Table 1. Thin films prepared by ALD for gas sensing application. Where capa is used for capacitive sensor; DBTDA for dibutyltin diacetate and YSZ for yttrium stabilized zirconia.

\begin{tabular}{|c|c|c|c|c|c|c|c|c|c|}
\hline \multirow[b]{2}{*}{ Material } & \multirow[b]{2}{*}{ Substrate } & \multicolumn{5}{|c|}{ ALD process } & \multirow[b]{2}{*}{ Tested gas } & \multirow[b]{2}{*}{$\begin{array}{l}\text { type } \\
\text { SC }\end{array}$} & \multirow[b]{2}{*}{ Ref. } \\
\hline & & Reactant 1 & $\begin{array}{c}\text { Reactant } \\
2\end{array}$ & $\begin{array}{c}\mathrm{T} \\
\left({ }^{\circ} \mathrm{C}\right)\end{array}$ & $\begin{array}{l}\text { Thickness } \\
(\mathrm{nm})\end{array}$ & $\begin{array}{c}\text { GPC } \\
\text { (nm/cycle) }\end{array}$ & & & \\
\hline \multirow{9}{*}{$\mathrm{SnO}_{2}$} & Quartz & $\mathrm{SnCl}_{4}$ & $\mathrm{H}_{2} \mathrm{O}$ & $\begin{array}{c}180- \\
300\end{array}$ & $\sim 111$ & $\begin{array}{c}0.018- \\
0.003\end{array}$ & $\mathrm{CO}$ & $\mathrm{n}$ & [7] \\
\hline & \multirow{2}{*}{$\alpha-\mathrm{Al}_{2} \mathrm{O}_{3}$} & $\mathrm{SnCl}_{4}$ & $\mathrm{H}_{2} \mathrm{O}_{2}$ & 600 & $8-80$ & 0.026 & $\mathrm{CO}$ & $\mathrm{n}$ & \multirow[t]{2}{*}{ [8] } \\
\hline & & $\mathrm{SnI}_{4}$ & $\mathrm{O}_{2}$ & 600 & $11-110$ & 0.11 & $\mathrm{CO}$ & $\mathrm{n}$ & \\
\hline & Hotplate & $\mathrm{SnCl}_{4}$ & $\mathrm{H}_{2} \mathrm{O}_{2}$ & $\begin{array}{l}250- \\
400 \\
\end{array}$ & $1.58-5.87$ & $0.025-0.08$ & $\mathrm{CO}$ & $n$ & [11] \\
\hline & $\mathrm{SiO}_{2} \mathrm{NPs}$ & $\mathrm{SnCl}_{4}$ & $\mathrm{H}_{2} \mathrm{O}_{2}$ & 325 & $1-3.5$ & 0.07 & $\mathrm{CO} ; \mathrm{O}_{2}$ & $\mathrm{n}$ & [15] \\
\hline & $\mathrm{SiO}_{2} / \mathrm{Si}$ & $\mathrm{SnCl}_{4}$ & $\mathrm{H}_{2} \mathrm{O}$ & 500 & $7-140$ & 0.035 & $\mathrm{C}_{2} \mathrm{H}_{5} \mathrm{OH}$ & $\mathrm{n}$ & [14] \\
\hline & Hotplate & $\mathrm{SnCl}_{4}$ & $\mathrm{H}_{2} \mathrm{O}$ & 500 & 17.5 & 0.035 & $\begin{array}{c}\mathrm{C}_{2} \mathrm{H}_{5} \mathrm{OH} ; \\
\mathrm{CH}_{3} \mathrm{COCH}_{3} ; \\
\mathrm{CH}_{2} \mathrm{CHCN}\end{array}$ & $\mathrm{n}$ & [9] \\
\hline & $\mathrm{Si}(100)$ & DBTDA & $\begin{array}{c}\mathrm{O}_{2} \\
\text { plasma }\end{array}$ & $\begin{array}{l}200- \\
400\end{array}$ & $10-40$ & $0.08-0,1$ & $\mathrm{CO}$ & $\mathrm{n}$ & {$[10,21]$} \\
\hline & $\mathrm{SiO}_{2} / \mathrm{Si}$ & $\mathrm{Sn}\left(\mathrm{NMe}_{2}\right)_{4}$ & $\mathrm{O}_{3}$ & 200 & 7 & - & $\begin{array}{c}\mathrm{O}_{3} ; \mathrm{CO} ; \\
\mathrm{NO}_{2}\end{array}$ & - & [22] \\
\hline $\begin{array}{c}\text { Epitaxial } \\
\mathrm{SnO}_{2}\end{array}$ & $\mathrm{TiO}_{2}$ & DBTDA & $\begin{array}{c}\mathrm{O}_{2} \\
\text { plasma }\end{array}$ & 300 & 90 & 0.09 & $\mathrm{H}_{2}$ & $\mathrm{n}$ & [23] \\
\hline$\frac{\mathrm{SnO}_{2} / \mathrm{TiO}_{2}}{\mathrm{TiO}_{2} / \mathrm{SnO}_{2}}$ & $\alpha-\mathrm{Al}_{2} \mathrm{O}_{3}$ & $\mathrm{Snl}_{4} / \mathrm{O}_{2}$ & $\mathrm{TiCl}_{4} / \mathrm{H}_{2} \mathrm{O}$ & 600 & $10-90$ & $0.1-0.05$ & $\begin{array}{c}\mathrm{H}_{2}, \mathrm{CO}, \\
\mathrm{CH}_{4}\end{array}$ & $n$ & [16] \\
\hline \multirow{3}{*}{$\mathrm{TiO}_{2}$} & $\mathrm{SiO}_{2} / \mathrm{Si}$ & $\mathrm{TiCl}_{4}$ & $\mathrm{H}_{2} \mathrm{O}$ & 150 & 5 & 0.088 & $\mathrm{H}_{2}$ & $\mathrm{n}$ & {$[18 b, 18 c]$} \\
\hline & QCM & $\mathrm{Ti}\left(\mathrm{O}^{\mathrm{i}} \mathrm{Pr}\right)_{4}$ & $\mathrm{H}_{2} \mathrm{O}$ & 200 & 8 & 0.053 & $\mathrm{NO}_{2}$ & - & [24] \\
\hline & glass & $\mathrm{TiCl}_{4}$ & $\mathrm{H}_{2} \mathrm{O}$ & 300 & $15-45$ & 0.045 & $\mathrm{H}_{2}$ & & {$[25]$} \\
\hline
\end{tabular}




\begin{tabular}{|c|c|c|c|c|c|c|c|c|c|}
\hline $\begin{array}{c}\text { Epitaxial } \\
\text { brookite } \\
\mathrm{TiO}_{2} \\
\end{array}$ & YSZ (110) & $\mathrm{Ti}\left(\mathrm{O}^{\mathrm{i}} \mathrm{Pr}\right)_{4}$ & $\begin{array}{c}\mathrm{O}_{2} \\
\text { plasma }\end{array}$ & 300 & 80 & 0.08 & $\begin{array}{c}\mathrm{H}_{2} ; \\
\mathrm{CO} ; \mathrm{NH}_{3} ; \\
\mathrm{C}_{2} \mathrm{H}_{5} \mathrm{OH}\end{array}$ & $\mathrm{n}$ & [18a] \\
\hline $\mathrm{TiO}_{2} / \mathrm{Al}_{2} \mathrm{O}_{3}$ & $\mathrm{p}-\mathrm{Si}$ & - & - & - & $3 ; 3$ & - & $\mathrm{NO}_{2} ; \mathrm{CO}_{2}$ & - & {$[26][27]$} \\
\hline \multirow{2}{*}{$\mathrm{Al}_{2} \mathrm{O}_{3}$} & $\mathrm{p}-\mathrm{Si}$ & - & - & - & 3 & - & $\mathrm{NO}_{2}$ & - & [27] \\
\hline & $4 \mathrm{H}-\mathrm{SiC}$ & - & - & 250 & 100 & - & $\mathrm{H}_{2} ; \mathrm{O}_{2}$ & capa & [28] \\
\hline$\alpha-\mathrm{Fe}_{2} \mathrm{O}_{3}$ & $\begin{array}{c}\text { Glass } \\
\text { with Pt } \\
\text { contact }\end{array}$ & $\mathrm{FeCl}_{3}$ & $\mathrm{H}_{2} \mathrm{O}$ & 500 & 100 & 0.02 & $\mathrm{CO} ; \mathrm{O}_{2}$ & $\mathrm{n}$ & [29] \\
\hline $\begin{array}{l}\mathrm{SrTiO}_{3} \\
(110)- \\
\text { oriented }\end{array}$ & $\begin{array}{l}\alpha-\mathrm{Al}_{2} \mathrm{O}_{3} \\
\text { (c-cut) }\end{array}$ & $\begin{array}{l}\operatorname{Sr}(\text { thd })_{2} / \\
\operatorname{Ti}\left(O^{\prime} \operatorname{Pr}\right)_{4}\end{array}$ & $\mathrm{O}_{2} / \mathrm{H}_{2} \mathrm{O}$ & 300 & 20 & - & $\mathrm{O}_{2}$ & - & [20] \\
\hline $\begin{array}{c}\text { Epitaxial } \\
\alpha-\mathrm{Cr}_{2} \mathrm{O}_{3} \\
(001)\end{array}$ & $\begin{array}{l}\alpha-\mathrm{Al}_{2} \mathrm{O}_{3} \\
\text { (c-cut) }\end{array}$ & $\mathrm{CrO}_{2} \mathrm{Cl}_{2}$ & $\mathrm{CH}_{3} \mathrm{OH}$ & 420 & $23-30$ & - & $\mathrm{H}_{2} ; \mathrm{CO}$ & $\mathrm{p}$ & [30] \\
\hline $\mathrm{Cr}_{2} \mathrm{O}_{3}-\mathrm{TiO}_{2}$ & $\begin{array}{l}\mathrm{Si}, \mathrm{SiO}_{2} \\
\alpha-\mathrm{Al}_{2} \mathrm{O}_{3} \\
\end{array}$ & $\begin{array}{c}\mathrm{CrO}_{2} \mathrm{Cl}_{2} \\
\mathrm{TiCl}_{4} \\
\end{array}$ & $\mathrm{CH}_{3} \mathrm{OH}$ & 420 & 70 & $\begin{array}{l}0.09 \\
0.04 \\
\end{array}$ & $\begin{array}{c}\mathrm{CH}_{4} ; \mathrm{H}_{2} ; \\
\mathrm{CO}\end{array}$ & & [31] \\
\hline \multirow{4}{*}{$\mathrm{ZnO}$} & $\mathrm{Al}_{2} \mathrm{O}_{3} / \mathrm{Si}$ & $\mathrm{Zn}\left(\mathrm{C}_{2} \mathrm{H}_{5}\right)_{2}$ & $\mathrm{H}_{2} \mathrm{O}$ & $\begin{array}{l}150- \\
200\end{array}$ & $5-50$ & - & $\mathrm{CO} ; \mathrm{O}_{2} ; \mathrm{RH}$ & - & {$[17 \mathrm{a}-\mathrm{c}, 32]$} \\
\hline & $\mathrm{Al}_{2} \mathrm{O}_{3} / \mathrm{Si}$ & $\mathrm{Zn}\left(\mathrm{C}_{2} \mathrm{H}_{5}\right)_{2}$ & $\begin{array}{c}\mathrm{O}_{2} \\
\text { plasma }\end{array}$ & $\begin{array}{l}150- \\
200\end{array}$ & $5-50$ & - & $\mathrm{CO} ; \mathrm{O}_{2} ; \mathrm{RH}$ & - & {$[17 c, 32]$} \\
\hline & $\begin{array}{c}100 \mathrm{~nm} \\
\mathrm{Al} / \text { quartz } \\
\text { Quartz } \\
\end{array}$ & $\mathrm{Zn}\left(\mathrm{C}_{2} \mathrm{H}_{5}\right)_{2}$ & $\mathrm{H}_{2} \mathrm{O}$ & $\begin{array}{l}165- \\
250\end{array}$ & $52.4-34.2$ & $0.21-0.14$ & $\mathrm{C}_{2} \mathrm{H}_{5} \mathrm{OH}$ & - & [17d] \\
\hline & $\mathrm{Si}_{3} \mathrm{~N}_{4} / \mathrm{Si}$ & - & - & - & 10 & - & $\begin{array}{c}\mathrm{NO}_{2} ; \mathrm{H}_{2} \mathrm{~S} ; \\
\mathrm{CO}_{2} ; \mathrm{NH}_{3} ; \\
\mathrm{SO}_{2} ; \mathrm{CH}_{4} ; \\
\mathrm{C}_{3} \mathrm{H}_{8}\end{array}$ & FET & [33] \\
\hline $\mathrm{La}_{2} \mathrm{O}_{3}$ & $\mathrm{Si}$ & $\mathrm{La}(\text { thd })_{3}$ & $\mathrm{O}_{3}$ & $\begin{array}{l}300 \\
350\end{array}$ & $\begin{array}{l}15 \\
10\end{array}$ & - & $\mathrm{CO}_{2}$ & capa & $\begin{array}{c}{[19 a, 32]} \\
{[19 b]}\end{array}$ \\
\hline La: $\mathrm{ZrO}_{2}$ & $4 \mathrm{H}-\mathrm{SiC}$ & $\begin{array}{l}\left(\mathrm{C}_{11} \mathrm{H}_{19} \mathrm{O}_{2}\right)_{3} \mathrm{La} \\
\left(\mathrm{C}_{2} \mathrm{H}_{6} \mathrm{~N}\right)_{4} \mathrm{Zr}\end{array}$ & $\mathrm{H}_{2} \mathrm{O}$ & 300 & - & - & $\mathrm{O}_{2}$ & capa & [34] \\
\hline $\mathrm{HfO}_{2} / \mathrm{Al}_{2} \mathrm{O}_{3}$ & $\mathrm{p}-\mathrm{Si}$ & - & - & & $3 ; 3$ & - & $\mathrm{CO} ; \mathrm{CO}_{2}$ & - & [35] \\
\hline $\mathrm{Pt} / \mathrm{Al}: \mathrm{ZnO}$ & & $\begin{array}{c}\mathrm{Zn}\left(\mathrm{C}_{2} \mathrm{H}_{5}\right)_{2}- \\
\mathrm{Al}\left(\mathrm{CH}_{3}\right)_{3} \\
(\mathrm{MeCp}) \mathrm{PtMe} \mathrm{M}_{3}\end{array}$ & $\begin{array}{c}\mathrm{H}_{2} \mathrm{O} \\
\mathrm{O}_{2} \\
\text { plasma }\end{array}$ & $\begin{array}{l}180 \\
\text { RT }\end{array}$ & 50 & - & $\mathrm{O}_{2}, \mathrm{RH}$ & - & [36] \\
\hline
\end{tabular}




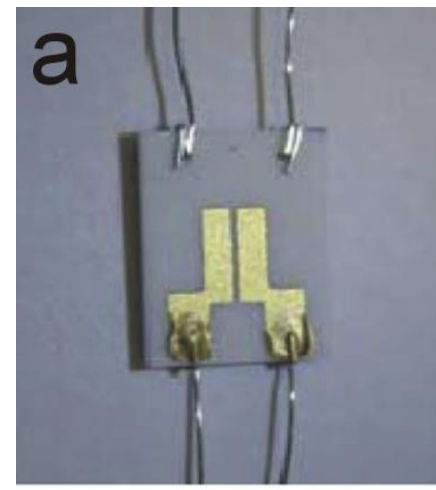

Front Side

C

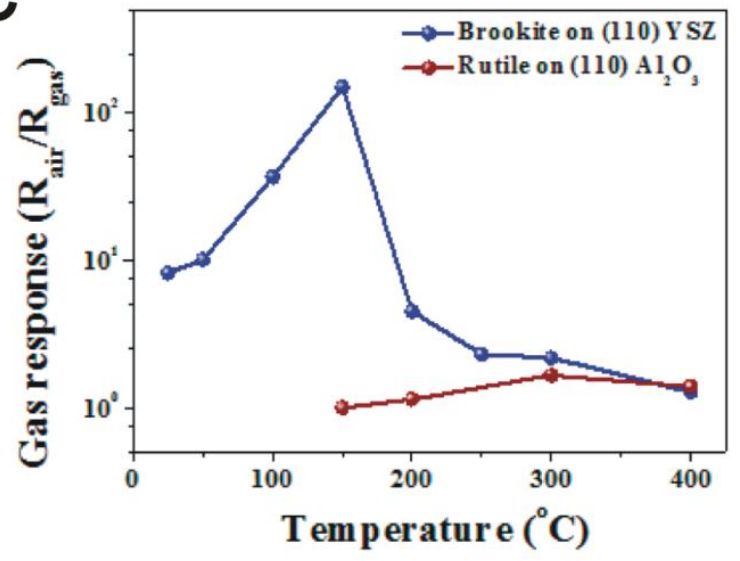

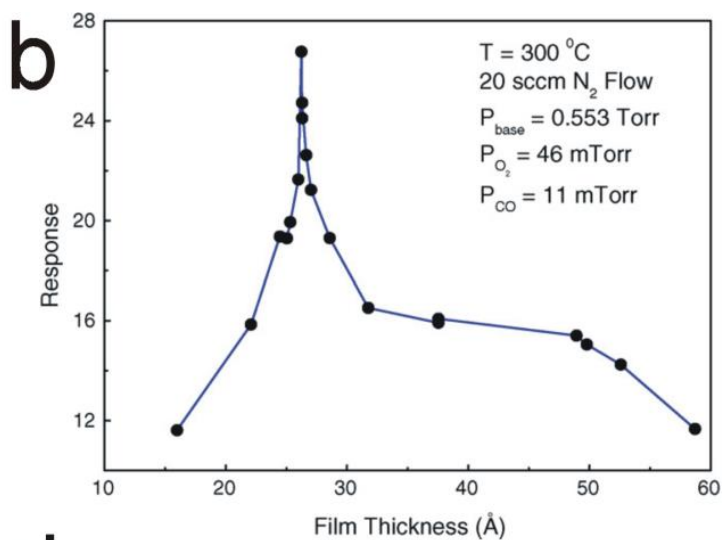

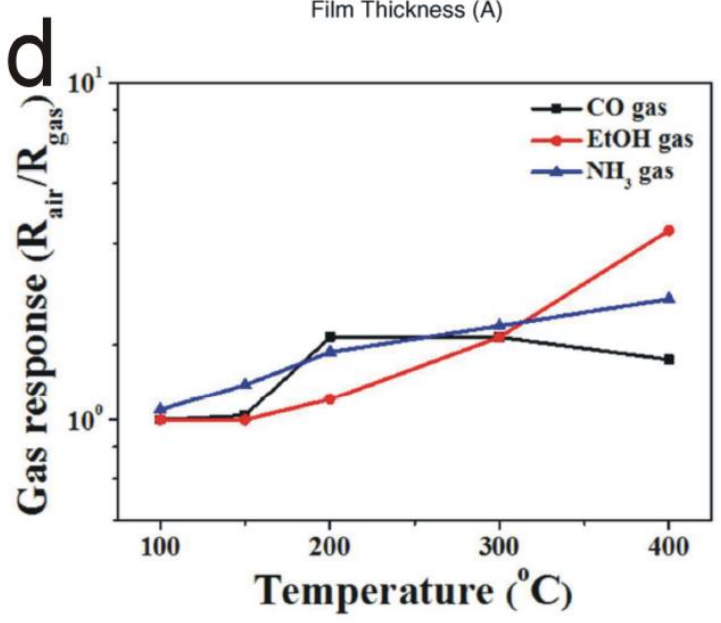

Figure 1. a) photograph of the sensing device used for $\mathrm{SnO}_{2}$ deposition. It shows patterned electrodes and heater on the front and back side, respectively. b) device response to 11 mtorr of $\mathrm{CO}$, at $300{ }^{\circ} \mathrm{C}$, as a function of the deposited film thickness. Reproduced with permission from $\operatorname{Ref}^{[11]}$. Gas responses as a function of the operating temperature c) of brookite and rutile $\mathrm{TiO}_{2}$ film toward $1000 \mathrm{ppm}$ of $\mathrm{H}_{2}$ and) of brookite film toward $1000 \mathrm{ppm}$ of $\mathrm{CO}$, ethanol and $\mathrm{NH}_{3}$. Reproduced with permission from Ref ${ }^{[18 a]}$. 


\section{Nanostructured materials as gas sensors}

The various nanostructures elaborated by ALD and used as sensing layer are listed in the Table 2. ZnO nanostructured materials presenting various morphologies have been synthesized by ALD and their gas sensing properties and transduction mechanism studied. Nanoscale spacer lithography combined to ZnO ALD was applied for the deposition of $\mathrm{ZnO}$ nanowire arrays (Figure 2a) field-effect transistor. The responses to $\mathrm{H}_{2}$ and $\mathrm{CO}$ in the range from 500 to $5000 \mathrm{ppm}$ were one order of magnitude higher than the ones measured for a compact thin film (cf. for example Figure $2 \mathrm{~b}$ for $\mathrm{H}_{2}$ detection). ${ }^{[37]}$
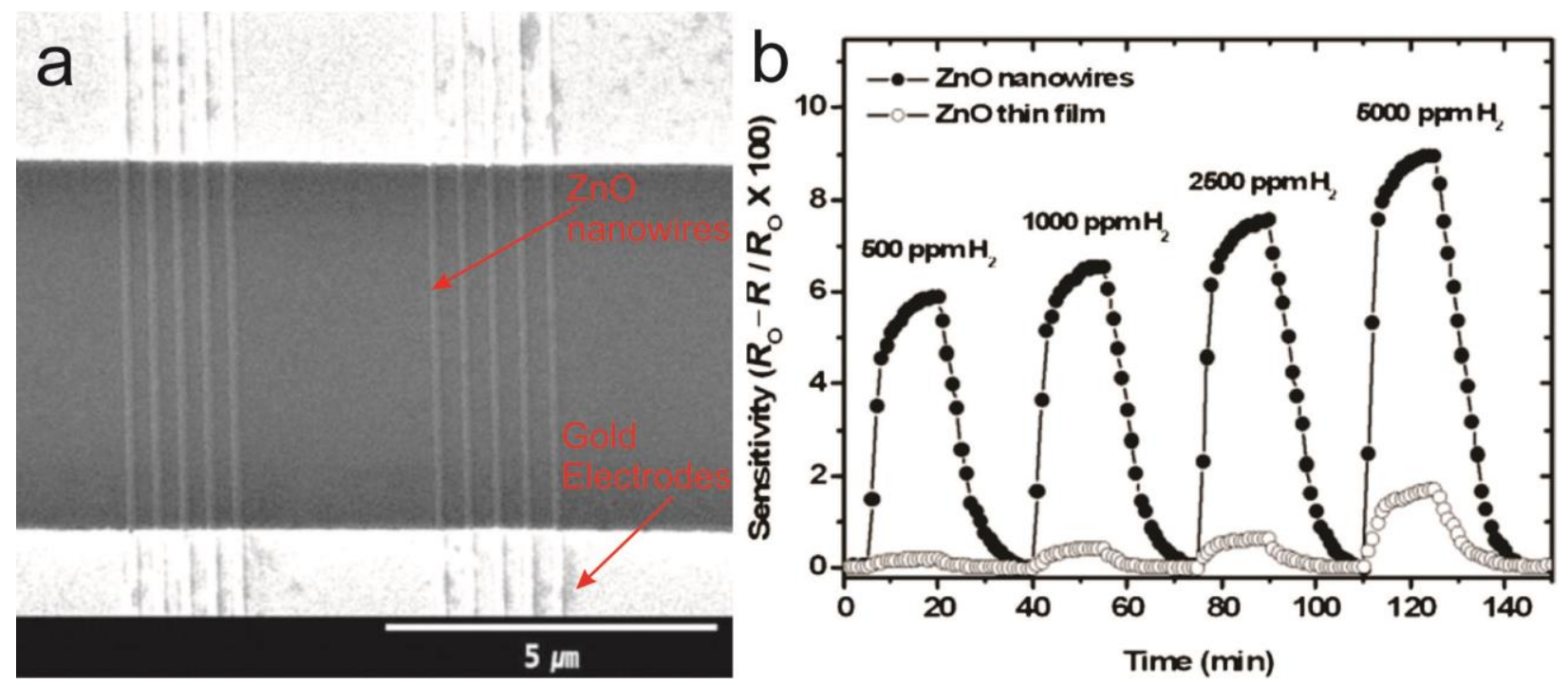

Figure 2. a) Scanning electron micrograph of the $\mathrm{ZnO}$ nanowire device, b) time dependence of the $\mathrm{H}_{2}$ sensitivity as function of time for the nanowire device and a compact $\mathrm{ZnO}$ thin film. Reproduced with permission from $\operatorname{Ref}^{[37]}$.

The same group compared the response to $\mathrm{H}_{2}$ of individual $\mathrm{ZnO}$ nanowires devices made of single crystalline or polycrystalline nanowires deposited by ALD. Contrarily to the single crystalline nanowire the latter presents multiple grain boundaries leading to a different sensing mechanism and performances. On the one hand, the polycrystalline nanowire-based device displays higher sensitivity, which is attributed to the grain boundaries potential barrier modulation of the response. On the other hand, the single crystalline nanowire-based device shows shorter response and recovery times due to the lower oxygen diffusion into grain boundaries affecting the response time of the polycrystalline nanowire-based device. ${ }^{[38]}$

Hollow $\mathrm{ZnO}$ nanofibers have been fabricated by several groups by coating electrospun polymer fibers using ZnO ALD followed by removal of the polymer template. ${ }^{[39]}$ The diameter of the cavity can be controlled by the diameter of the electrospun fiber and the thickness of the walls of the hollow $\mathrm{ZnO}$ fibers by the number of ALD cycles as shown in Figure 3a-d. ${ }^{[39 a]}$ Finally, the ZnO grain size can be controlled by post-deposition annealing at different temperatures. All these controllable parameters could allow to develop interesting structure-properties correlations in gas sensor devices, unfortunately, in this first report the authors compared the gas sensing response towards various gases of only one 
hollow nanofiber sample to a compact $\mathrm{ZnO}$ nanofiber. For example, the response towards $\mathrm{CO}$ is shown in Figure 3e. ${ }^{[39 a]}$ The improved response is attributed to the larger surface-to-volume ratio of the hollow fibers compared to a compact fiber.
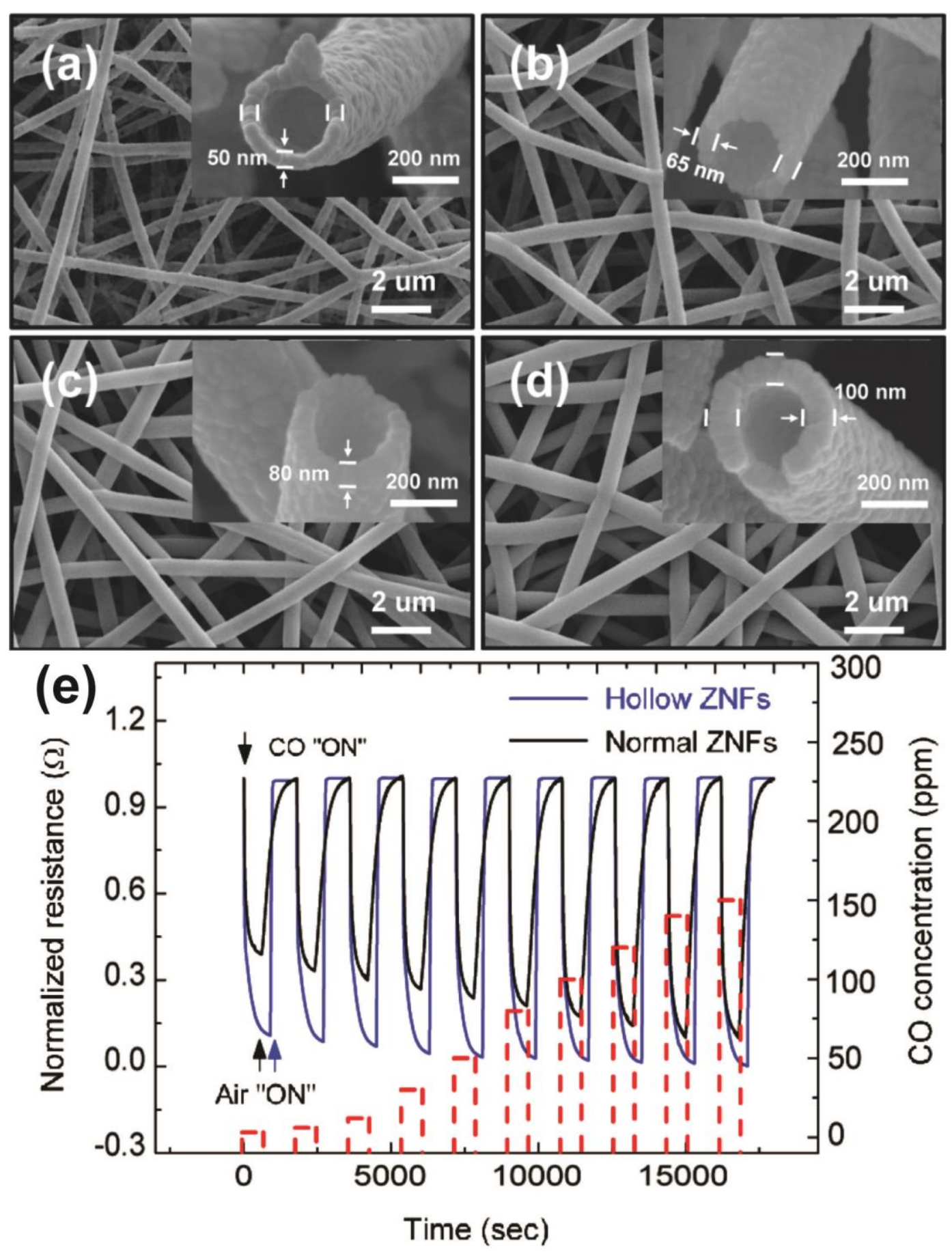

Figure 3. SEM images of hollow ZnO nanofibers prepared with different ALD cycles: a) 300, b) 400, c) 500, and d) 600 cycles. e) Comparison of the dynamic response to $\mathrm{CO}$ of hollow and compact $\mathrm{ZnO}$ nanofibers. Reproduced with permission from $\operatorname{Ref}^{[39 a]}$. 
The effect of the wall thickness on the sensitivity and response time was firstly highlighted by Cho et al. ${ }^{[39 b]}$ They found that hollow ZnO nanofibers with the thinnest walls $(10 \mathrm{~nm})$ display both higher sensitivities and lower response time to ethanol. The improved sensitivity is attributed to the fact that the thickness of the electron depletion layer is comparable to the thickness of the $\mathrm{ZnO}$ walls, leading to a stronger variation of the resistivity when the material is exposed to the analyte. Katoch et al. also investigated the wall thickness dependence of hollow $\mathrm{ZnO}$ nanofibers towards $\mathrm{CO}$ sensing. ${ }^{[39 \mathrm{c}]}$ Their results are in agreement with previous study showing that the thinner the wall thickness is, the higher the sensitivity and lower the response time are. Furthermore, by varying the composition of the electrospun solution, polymer fibers of different diameter can be obtained. After ALD and template removal, hollow $\mathrm{ZnO}$ fiber with various inner diameters can then be easily fabricated. It was shown that a smaller inner diameter leads to a higher active surface area and thus to a higher gas response. ${ }^{[40]}$ Electrospinning combined with ALD was also applied to fabricate $\mathrm{SnO}_{2}$ hollow nanofibers. To coat the electrospun polyacrylonitrile fibers, a low temperature $\left(100{ }^{\circ} \mathrm{C}\right)$ oxygen plasma-assisted ALD process using dibutyltindiacetate as tin precursor was carried out, after thermal annealing at $700{ }^{\circ} \mathrm{C}$ hollow and polycrystalline $\mathrm{SnO}_{2}$ nanofibers were obtained. Wall thicknesses ranging from 8 to $37 \mathrm{~nm}$ could be easily controlled by the number of ALD cycles. As already demonstrated above for ZnO hollow nanofibers, also in this case the sensitivity was highest and the response fastest for the fibers having the thinnest wall thickness. ${ }^{[41]}$ The ALD coating of twisted aligned electrospun polyacrylonitrile fibers leads, after thermal annealing, to polycrystalline and hollow $\mathrm{SnO}_{2}$ nanofibers microyarns. ${ }^{[42]}$ Their use as active material to $100 \mathrm{ppm} \mathrm{H}_{2}$ sensing was also demonstrated. Metal oxide $\left(\mathrm{TiO}_{2}, \mathrm{Al}_{2} \mathrm{O}_{3}\right.$ and $\left.\mathrm{ZnO}\right)$ nanotube aerogels were fabricated by coating nanofibrillated cellulose by ALD followed by removal of the cellulose aerogel template by thermal treatment at $450{ }^{\circ} \mathrm{C}$. The as-obtained $\mathrm{TiO}_{2}$ nanotube-based aerogel was used as active material for resistive humidity sensor. ${ }^{[43]}$

A hydrogen sensor based on a $\mathrm{ZnO}$ nanorod array was fabricated by impregnating an anodic aluminum oxide template, supported on a niobium electrode, by ZnO ALD followed by dissolution of the template in an acid. ${ }^{[44]} \mathrm{ZnO}$ nanowires displaying high-index polar zigzagged surfaces were fabricating in 3 steps (Figure $4 a){ }^{[45]}$ i) c-axis oriented single crystal nanowires were grown by physical vapor deposition. ii) They were then coated by ZnO ALD (Figure 4b) leading to a polycrystalline ZnO coating. iii) After a thermal annealing at $800{ }^{\circ} \mathrm{C}$ zigzagged nanowires displaying high-index and polar facets are obtained (Figure 4c,d). While single crystal ZnO nanowires exposing non-polar and low energy facets are nonresponsive to ozone, the zigzagged nanowires exhibit significant ozone sensitivities at ppb level due to the inherent defect rich high-index polar surfaces. 

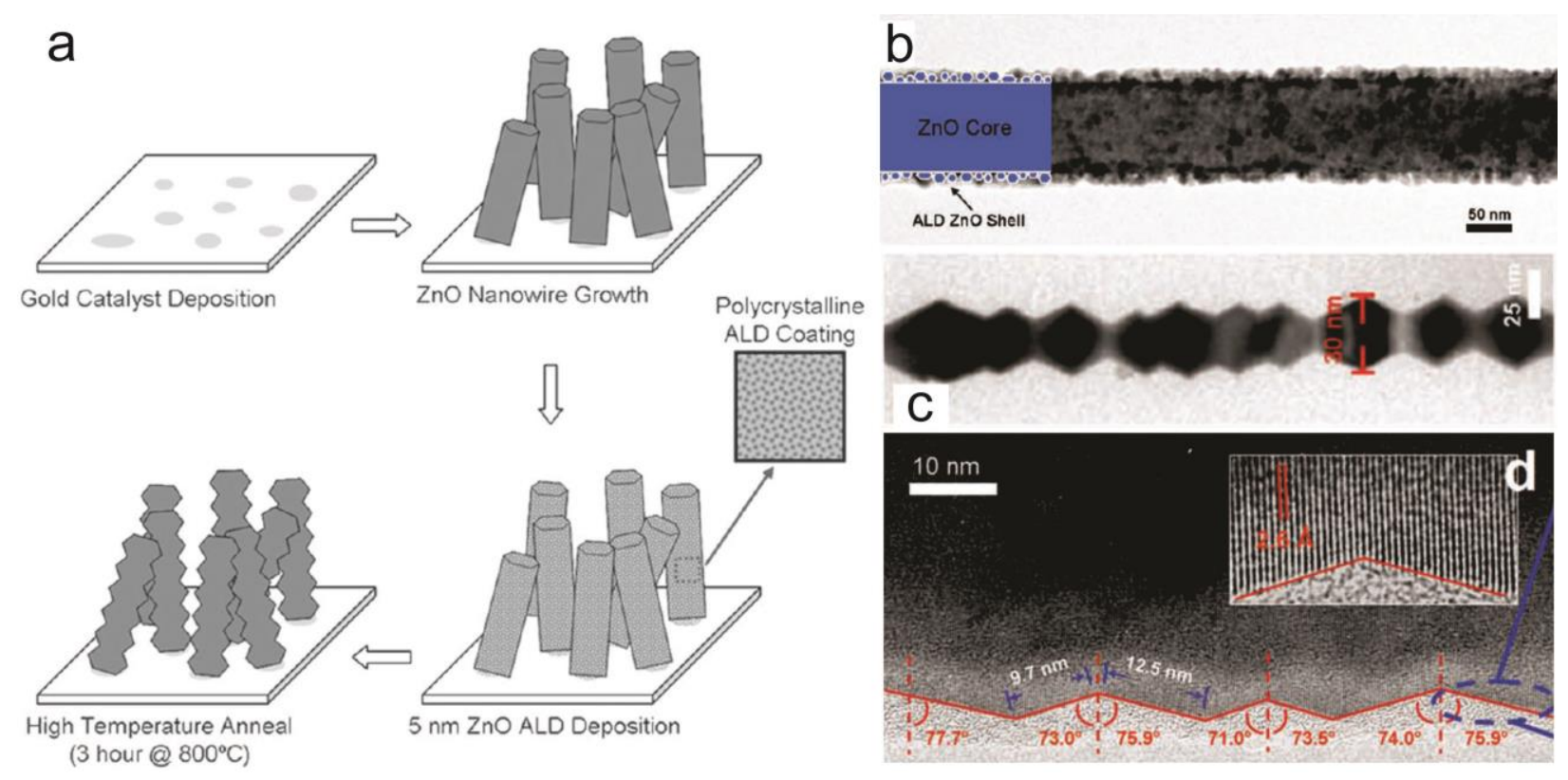

Figure 4. a) Scheme of the fabrication process of the zigzagged nanowires, b) TEM image of a single crystal ZnO nanowire core coated by polycrystalline ZnO ALD film, c,d) TEM and HRTEM images of a zigzagged nanowire after thermal annealing. Reproduced with permission from Ref. ${ }^{[45]}$ 
Table 2. Nanostructures prepared by ALD for gas sensing application, where capa means capacitive sensor; ES is used for electrospun and DBTDA for dibutyltin diacetate.

\begin{tabular}{|c|c|c|c|c|c|c|c|c|c|c|}
\hline \multirow[b]{2}{*}{ Material } & \multirow[b]{2}{*}{$\begin{array}{l}\text { Template } \\
\text { /support }\end{array}$} & \multicolumn{5}{|c|}{ ALD process } & \multirow{2}{*}{$\begin{array}{l}\text { Template } \\
\text { removal/ } \\
\text { structurati } \\
\text { on }\end{array}$} & \multirow[b]{2}{*}{$\begin{array}{l}\text { Tested } \\
\text { gas }\end{array}$} & \multirow[b]{2}{*}{$\begin{array}{l}\text { SC } \\
\text { type }\end{array}$} & \multirow[b]{2}{*}{ Ref. } \\
\hline & & $\begin{array}{c}\text { Reactant } \\
1\end{array}$ & $\begin{array}{c}\text { Reactant } \\
2\end{array}$ & $\begin{array}{c}\mathrm{T} \\
\left({ }^{\circ} \mathrm{C}\right)\end{array}$ & $\begin{array}{l}\text { Thickness } \\
(\mathrm{nm})\end{array}$ & $\begin{array}{c}\text { GPC } \\
\text { (nm/cycle) }\end{array}$ & & & & \\
\hline Pd NPs & $\begin{array}{c}\mathrm{AAO} \text { w/wo } \\
1 \mathrm{~nm} \mathrm{ALD} \\
\mathrm{Al}_{2} \mathrm{O}_{3}\end{array}$ & $\mathrm{Pd}(\mathrm{hfac})_{2}$ & $\mathrm{HCOH}$ & 200 & 2 & - & none & $\mathrm{H}_{2}$ & - & [46] \\
\hline $\begin{array}{c}\text { ZnO NW } \\
\text { array }\end{array}$ & $\begin{array}{l}\text { Patterned } \\
\mathrm{SiO}_{2} /\end{array}$ & - & - & - & $70-100$ & - & $\begin{array}{c}\text { photolitho } \\
\text { graphy }\end{array}$ & $\mathrm{CO} ; \mathrm{H}_{2}$ & FET & $\begin{array}{l}{[37]} \\
{[38]}\end{array}$ \\
\hline ZnO fibers & $\begin{array}{c}\text { ES-PVA } \\
\text { fibers }\end{array}$ & $\mathrm{Zn}\left(\mathrm{C}_{2} \mathrm{H}_{5}\right)_{2}$ & $\mathrm{H}_{2} \mathrm{O}$ & 150 & $50-100$ & 0.165 & $>400^{\circ} \mathrm{C}$ & $\begin{array}{c}\mathrm{CO} ; \mathrm{O}_{2} ; \\
\mathrm{NO}_{2}\end{array}$ & $\mathrm{n}$ & [39a] \\
\hline ZnO NTs & $\begin{array}{l}\text { ES-PAN } \\
\text { fibers }\end{array}$ & $\mathrm{Zn}\left(\mathrm{C}_{2} \mathrm{H}_{5}\right)_{2}$ & $\mathrm{H}_{2} \mathrm{O}$ & 150 & $10-50$ & 0.2 & $\begin{array}{r}\mathrm{O}_{2} \text { plasma } \\
+500^{\circ} \mathrm{C} 2 \mathrm{~h} \\
\end{array}$ & $\begin{array}{c}\mathrm{H}_{2} ; \\
\mathrm{C}_{2} \mathrm{H}_{5} \mathrm{OH}\end{array}$ & $n$ & [39b] \\
\hline $\begin{array}{l}\text { Zigzagged } \\
\text { ZnO NWs }\end{array}$ & ZnO NW & $\mathrm{Zn}\left(\mathrm{C}_{2} \mathrm{H}_{5}\right)_{2}$ & $\mathrm{H}_{2} \mathrm{O}$ & 150 & 5 & - & $800^{\circ} \mathrm{C} 3 \mathrm{~h}$ & $\mathrm{O}_{3}$ & $n$ & [45] \\
\hline $\begin{array}{c}\text { ZnO NW } \\
\text { array }\end{array}$ & AAO & $\mathrm{Zn}\left(\mathrm{C}_{2} \mathrm{H}_{5}\right)_{2}$ & $\mathrm{H}_{2} \mathrm{O}$ & 200 & 600 & & $\begin{array}{l}\mathrm{H}_{3} \mathrm{PO}_{4} / \\
\mathrm{H}_{2} \mathrm{CrO}_{4}\end{array}$ & $\mathrm{H}_{2}$ & $n$ & [44] \\
\hline $\begin{array}{c}\text { ZnO NW } \\
\text { array }\end{array}$ & AAO & $\mathrm{Zn}\left(\mathrm{C}_{2} \mathrm{H}_{5}\right)_{2}$ & $\mathrm{H}_{2} \mathrm{O}$ & 200 & - & - & $\mathrm{NaOH}$ & $\mathrm{NH}_{3}$ & capa & {$[47]$} \\
\hline ZnO NTs & $\begin{array}{l}\text { ES-PVA } \\
\text { fibers }\end{array}$ & $\mathrm{Zn}\left(\mathrm{C}_{2} \mathrm{H}_{5}\right)_{2}$ & $\mathrm{H}_{2} \mathrm{O}$ & 150 & $50-120$ & 0.14 & $\begin{array}{c}500^{\circ} \mathrm{C} \\
0.5 \mathrm{~h}\end{array}$ & $\begin{array}{c}\mathrm{CO} ; \mathrm{H}_{2} ; \\
\mathrm{NO}_{2}\end{array}$ & $n$ & $\begin{array}{c}{[399,} \\
40]\end{array}$ \\
\hline $\begin{array}{c}\mathrm{ZnO} / \mathrm{TiO}_{2} \\
\text { NTs }\end{array}$ & $\begin{array}{l}\text { ES-PVA } \\
\text { fibers }\end{array}$ & $\begin{array}{l}\mathrm{Ti}\left(\mathrm{O}^{\mathrm{i}} \mathrm{Pr}\right)_{4} / \\
\mathrm{Zn}\left(\mathrm{C}_{2} \mathrm{H}_{5}\right)_{2}\end{array}$ & $\begin{array}{l}\mathrm{H}_{2} \mathrm{O} / \\
\mathrm{H}_{2} \mathrm{O} \\
\end{array}$ & 150 & $\begin{array}{c}30 \\
3-70 \\
\end{array}$ & $\begin{array}{c}0.03 \\
0.2 \\
\end{array}$ & $\begin{array}{c}500{ }^{\circ} \mathrm{C} \\
0.5 \mathrm{~h}\end{array}$ & $\begin{array}{l}\mathrm{CO} ; \\
\mathrm{NO}_{2} \\
\end{array}$ & $n$ & [48] \\
\hline $\begin{array}{l}\mathrm{ZnO} N \mathrm{NT} \\
\text { aerogel }\end{array}$ & $\begin{array}{c}\text { Nano- } \\
\text { cellulose }\end{array}$ & $\mathrm{Zn}\left(\mathrm{C}_{2} \mathrm{H}_{5}\right)_{2}$ & $\mathrm{H}_{2} \mathrm{O}$ & 150 & $5-30$ & $0.09-0.11$ & $450^{\circ} \mathrm{C}$ & $\mathrm{RH}$ & capa & [43] \\
\hline $\begin{array}{l}\mathrm{TiO}_{2} \mathrm{NT} \\
\text { aerogel } \\
\end{array}$ & $\begin{array}{c}\text { Nano- } \\
\text { cellulose }\end{array}$ & $\mathrm{TiCl}_{4}$ & $\mathrm{H}_{2} \mathrm{O}$ & 150 & $5-30$ & $0.09-0.11$ & $450^{\circ} \mathrm{C}$ & $\mathrm{RH}$ & capa & [43] \\
\hline $\begin{array}{c}\mathrm{Al}_{2} \mathrm{O}_{3} \mathrm{NT} \\
\text { aerogel }\end{array}$ & $\begin{array}{c}\text { Nano- } \\
\text { cellulose }\end{array}$ & $\mathrm{Al}\left(\mathrm{CH}_{3}\right)_{3}$ & $\mathrm{H}_{2} \mathrm{O}$ & 150 & $5-30$ & $0.09-0.11$ & $450^{\circ} \mathrm{C}$ & $\mathrm{RH}$ & capa & {$[43]$} \\
\hline $\begin{array}{c}\text { porous } \\
\mathrm{Al}_{2} \mathrm{O}_{3} \\
\text { network }\end{array}$ & $\begin{array}{c}\text { Porous } \\
\text { block- } \\
\text { copolymer }\end{array}$ & $\mathrm{Al}\left(\mathrm{CH}_{3}\right)_{3}$ & $\mathrm{H}_{2} \mathrm{O}$ & 70 & $0-20$ & 0.16 & $540^{\circ} \mathrm{C} 8 \mathrm{~h}$ & $\mathrm{RH}$ & 기 & [49] \\
\hline $\begin{array}{c}\mathrm{Al}_{2} \mathrm{O}_{3} \\
\text { aerogel }\end{array}$ & CNT foam & $\mathrm{Al}\left(\mathrm{CH}_{3}\right)_{3}$ & $\mathrm{H}_{2} \mathrm{O}$ & & 2.5 & 0.012 & $800^{\circ} \mathrm{C} 2 \mathrm{~h}$ & $\mathrm{RH}$ & ווד & [50] \\
\hline $\mathrm{Al}_{2} \mathrm{O}_{3} \mathrm{NTs}$ & $\begin{array}{c}\text { CNTs } \\
\text { AC-CNTs }\end{array}$ & $\mathrm{Al}\left(\mathrm{CH}_{3}\right)_{3}$ & $\mathrm{H}_{2} \mathrm{O}$ & 120 & $3-30$ & 0.13 & $650^{\circ} \mathrm{C} 1 \mathrm{~h}$ & $\mathrm{RH}$ & ㅈI & [51] \\
\hline $\mathrm{SnO}_{2} \mathrm{NT}$ & $\begin{array}{l}\text { ES-PAN } \\
\text { fibers }\end{array}$ & DBTDA & $\begin{array}{c}\mathrm{O}_{2} \\
\text { plasma }\end{array}$ & 100 & $8-37$ & 0.08 & $700^{\circ} \mathrm{C} 1 \mathrm{~h}$ & $\begin{array}{c}\mathrm{NH}_{3} ; \\
\mathrm{NO}_{2} ; \\
\mathrm{CO} ; \mathrm{H}_{2} ; \\
\mathrm{C}_{2} \mathrm{H}_{5} \mathrm{OH}\end{array}$ & $n$ & [41] \\
\hline $\begin{array}{c}\mathrm{SnO}_{2} \\
\text { microyarn }\end{array}$ & $\begin{array}{l}\text { ES-PAN } \\
\text { fibers }\end{array}$ & DBTDA & $\begin{array}{c}\mathrm{O}_{2} \\
\text { plasma }\end{array}$ & - & 70 & 0.07 & $700^{\circ} \mathrm{C} 1 \mathrm{~h}$ & $\mathrm{H}_{2}$ & $n$ & [42] \\
\hline $\begin{array}{c}\text { Porous } \\
\mathrm{SnO}_{2} \\
\end{array}$ & Porous Au & $\begin{array}{c}\mathrm{Sn}\left(\mathrm{Nme}_{2}\right) \\
4\end{array}$ & $\mathrm{O}_{3}$ & 100 & 36 & 0.12 & Aqua regia & $\begin{array}{c}\mathrm{H}_{2} ; \\
\mathrm{C}_{2} \mathrm{H}_{5} \mathrm{OH}\end{array}$ & $n$ & [52] \\
\hline $\mathrm{TiO}_{2}$ & AAO & $\mathrm{TiCl}_{4}$ & $\mathrm{H}_{2} \mathrm{O}$ & 150 & 20 & 0.067 & $\begin{array}{c}\text { Epoxy + } \\
\mathrm{HgCl}_{2}+1 \mathrm{~h} \\
0.1 \mathrm{M} \mathrm{KOH} \\
\end{array}$ & $\begin{array}{c}\mathrm{H}_{2} ; \mathrm{CO} ; \\
\mathrm{NH}_{3} ; \\
\mathrm{C}_{2} \mathrm{H}_{5} \mathrm{OH}\end{array}$ & $n$ & [53] \\
\hline $\mathrm{Ta}_{2} \mathrm{O}_{5}$ & Porous Si & - & - & - & 95 & - & none & $\mathrm{RH}$ & capa & [54] \\
\hline
\end{tabular}


$\mathrm{HfO}_{2}$

Porous $\mathrm{Si}$

100

none

\begin{tabular}{l|l|}
$\mathrm{RH}$ & capa \\
\hline
\end{tabular}

$[55]$

\section{Heterostructured gas sensors}

Gas sensors based on heterojunctions and consisting of a core/shell (CS) morphology have been widely investigated. Interactions between the deposited material (the shell) and the support (the core) can drastically change the properties of the hetero-structures and improved sensing properties compared to their single components have been highlighted. Especially, when the thickness of the shell material is in the range of the Debye length, a synergetic effect is observed. This phenomenon is attributed to band bending and transfer of the charge carriers between the shell and the core material. Depending on the type of junction involved, heterojunction-based gas sensors can be divided into three different categories: $n-n, p-n$ or $n-p$ heterojunctions and metal-semiconductor heterojunction.

ALD has proved to be suited for the elaboration of shell material with a precise control of the thickness and composition. It has then been applied for CS-based gas sensor, allowing the study of the influence of the thickness of the shell on the sensing performances. ${ }^{[56]}$ The various heterostructures fabricated using ALD and applied to gas sensing are reported in the Table 3. Examples of ALD structures for each type of junction and the discussion on their sensing mechanisms are presented in the following subsections. Core-shell materials for optical detection of gases are also introduced at the end of the section.

Table 3. Core-shell heterostructures prepared by ALD for gas sensing application. Where capa means capacitive sensor, DBTDA dibutyltin diacetate and ES electrospun.

\begin{tabular}{|c|c|c|c|c|c|c|c|c|c|}
\hline \multirow{2}{*}{$\begin{array}{l}\text { Material } \\
\text { (shell) }\end{array}$} & \multirow{2}{*}{$\begin{array}{l}\text { Substrate } \\
\text { (core) }\end{array}$} & \multicolumn{5}{|c|}{ ALD process } & \multirow[b]{2}{*}{ Tested gas } & \multirow{2}{*}{$\begin{array}{l}\text { Junction } \\
\text { type }\end{array}$} & \multirow[b]{2}{*}{ Ref. } \\
\hline & & Reactant 1 & Reactant 2 & $\begin{array}{c}\mathrm{T} \\
\left({ }^{\circ} \mathrm{C}\right)\end{array}$ & $\begin{array}{l}\text { Thickness } \\
\text { (nm) }\end{array}$ & $\begin{array}{c}\text { GPC } \\
\text { (nm/cycle) }\end{array}$ & & & \\
\hline $\mathrm{V}_{2} \mathrm{O}_{4}$ & MWCNTs & $\mathrm{VO}\left(\mathrm{O}^{\mathrm{n}} \mathrm{Pr}\right)_{3}$ & $\mathrm{CH}_{3} \mathrm{COOH}$ & 200 & $2-5$ & 0.04 & $\mathrm{NO}_{2}$ & $n-p$ & {$[57][58]$} \\
\hline $\mathrm{ZnO}$ & $\begin{array}{c}\text { Carbon post } \\
\text { array }\end{array}$ & $\mathrm{Zn}\left(\mathrm{C}_{2} \mathrm{H}_{5}\right)_{2}$ & $\mathrm{H}_{2} \mathrm{O}$ & - & 20 & - & $\mathrm{H}_{2}$ & - & [59] \\
\hline $\mathrm{ZnO}$ & graphene & $\mathrm{Zn}\left(\mathrm{C}_{2} \mathrm{H}_{5}\right)_{2}$ & $\mathrm{H}_{2} \mathrm{O}$ & 80 & $0.5-10$ & 0.1 & $\mathrm{HCHO} ; \mathrm{NO}_{2}$ & $n-p$ & {$[60][61]$} \\
\hline $\mathrm{ZnO}$ & ES-SnO ${ }_{2}$ fibers & $\mathrm{Zn}\left(\mathrm{C}_{2} \mathrm{H}_{5}\right)_{2}$ & $\mathrm{H}_{2} \mathrm{O}$ & 150 & $\begin{array}{c}\sim 22-250 \\
5-120\end{array}$ & $\begin{array}{l}0,45 \\
0.24\end{array}$ & $\mathrm{O}_{2} ; \mathrm{NO}_{2} ; \mathrm{CO}$ & $n-n$ & $\begin{array}{c}{[62][63]} \\
{[56 b]}\end{array}$ \\
\hline $\begin{array}{c}\mathrm{ZnO}(\mathrm{w} / \mathrm{o} \mathrm{Pd} \\
\mathrm{NPs})\end{array}$ & $\mathrm{SnO}_{2} \mathrm{NRs}$ & $\mathrm{Zn}\left(\mathrm{C}_{2} \mathrm{H}_{5}\right)_{2}$ & $\mathrm{H}_{2} \mathrm{O}$ & 150 & 3 & - & $\mathrm{H}_{2} \mathrm{~S}$ & $n-n$ & [64] \\
\hline $\mathrm{ZnO}$ & $\mathrm{SnO}_{2} \mathrm{NRs}$ & $\mathrm{Zn}\left(\mathrm{C}_{2} \mathrm{H}_{5}\right)_{2}$ & $\mathrm{H}_{2} \mathrm{O}$ & 150 & 10 & 0.2 & $\mathrm{NO}_{2}$ & $n-n$ & [65] \\
\hline $\mathrm{ZnO}$ & $\mathrm{SnO}_{2} \mathrm{NRs}$ & $\mathrm{Zn}\left(\mathrm{C}_{2} \mathrm{H}_{5}\right)_{2}$ & $\mathrm{H}_{2} \mathrm{O}$ & 150 & $3.5-95$ & - & $\begin{array}{l}\mathrm{CO} ; \mathrm{NO}_{2} ; \\
\mathrm{C}_{7} \mathrm{H}_{8} ; \mathrm{C}_{6} \mathrm{H}_{6}\end{array}$ & $n-n$ & [56a] \\
\hline $\mathrm{ZnO}$ & $\mathrm{TiO}_{2} \mathrm{NRs}$ & $\mathrm{Zn}\left(\mathrm{C}_{2} \mathrm{H}_{5}\right)_{2}$ & $\mathrm{H}_{2} \mathrm{O}$ & 150 & 20 & 0.4 & $\mathrm{C}_{2} \mathrm{H}_{5} \mathrm{OH}$ & $n-n$ & [66] \\
\hline $\mathrm{ZnO}$ & $\mathrm{ES}^{-\mathrm{TiO}_{2}}$ fibers & $\mathrm{Zn}\left(\mathrm{C}_{2} \mathrm{H}_{5}\right)_{2}$ & $\mathrm{H}_{2} \mathrm{O}$ & 150 & $50-250$ & 0.66 & $\mathrm{O}_{2}$ & $n-n$ & 67 \\
\hline $\mathrm{ZnO}$ & $\mathrm{WO}_{3} \mathrm{NRs}$ & $\mathrm{Zn}\left(\mathrm{C}_{2} \mathrm{H}_{5}\right)_{2}$ & $\mathrm{H}_{2} \mathrm{O}$ & 150 & 15 & 0.3 & $\mathrm{NO}_{2}$ & $n-n$ & {$[68]$} \\
\hline $\begin{array}{c}\mathrm{ZnO}+\mathrm{M} \\
\text { decoration }\end{array}$ & $\begin{array}{c}\mathrm{SiO}_{2} \\
\text { nanosprings }\end{array}$ & $\mathrm{Zn}\left(\mathrm{C}_{2} \mathrm{H}_{5}\right)_{2}$ & $\mathrm{H}_{2} \mathrm{O}$ & $\begin{array}{c}170 \\
- \\
175\end{array}$ & $3-100$ & - & $\begin{array}{c}\text { TNT; TATP; } \\
\mathrm{C}_{7} \mathrm{H}_{8} ; \\
\mathrm{C}_{2} \mathrm{H}_{5} \mathrm{OH} ; \\
\mathrm{CH}_{3} \mathrm{COCH}_{3}\end{array}$ & $M-n-I$ & [69] \\
\hline $\mathrm{ZnO}$ & $\mathrm{Ga}_{2} \mathrm{O}_{3} \mathrm{NWs}$ & $\mathrm{Zn}\left(\mathrm{C}_{2} \mathrm{H}_{5}\right)_{2}$ & $\mathrm{H}_{2} \mathrm{O}$ & 150 & $10-13$ & 0.2 & $\mathrm{NO}_{2}$ & $n-n$ & {$[56 f, 70]$} \\
\hline $\mathrm{ZnO}$ & GaN NWs & $\mathrm{Zn}\left(\mathrm{C}_{2} \mathrm{H}_{5}\right)_{2}$ & $\mathrm{H}_{2} \mathrm{O}$ & 150 & 8 & 0.4 & $\mathrm{H}_{2}$ & $n-n$ & [71] \\
\hline $\mathrm{ZnO}$ & CuO NRs & $\mathrm{Zn}\left(\mathrm{C}_{2} \mathrm{H}_{5}\right)_{2}$ & $\mathrm{H}_{2} \mathrm{O}$ & 150 & $\begin{array}{c}9 \\
5-110 \\
\end{array}$ & 0.06 & $\begin{array}{c}\mathrm{NO}_{2} \\
\mathrm{CO} ; \mathrm{C}_{6} \mathrm{H}_{6}\end{array}$ & $n-p$ & $\begin{array}{l}{[72]} \\
{[56 \mathrm{~d}]}\end{array}$ \\
\hline $\mathrm{ZnO}$ & ES-CuO fibers & $\mathrm{Zn}\left(\mathrm{C}_{2} \mathrm{H}_{5}\right)_{2}$ & $\mathrm{H}_{2} \mathrm{O}$ & 150 & $5-200$ & - & $\mathrm{CO}$ & $n-p$ & [73] \\
\hline $\mathrm{ZnO}$ & ZnS NWs & $\mathrm{Zn}\left(\mathrm{C}_{2} \mathrm{H}_{5}\right)_{2}$ & $\mathrm{H}_{2} \mathrm{O}$ & 150 & 7 & 0.14 & $\mathrm{NO}_{2} ; \mathrm{NH}_{3} ;$ & $n-n$ & {$[74]$} \\
\hline
\end{tabular}




\begin{tabular}{|c|c|c|c|c|c|c|c|c|c|}
\hline & & & & & & & $\mathrm{H}_{2} \mathrm{~S} ; \mathrm{C}_{2} \mathrm{H}_{5} \mathrm{OH}$ & & \\
\hline $\mathrm{ZnO}$ & $\mathrm{Zn}_{2} \mathrm{SnO}_{4} \mathrm{NRs}$ & $\mathrm{Zn}\left(\mathrm{C}_{2} \mathrm{H}_{5}\right)_{2}$ & $\mathrm{H}_{2} \mathrm{O}$ & 150 & 20 & - & $\mathrm{NO}_{2}$ & $n-n$ & [75] \\
\hline $\mathrm{ZnO}$ & $\mathrm{In}_{2} \mathrm{O}_{3} \mathrm{NWs}$ & $\mathrm{Zn}\left(\mathrm{C}_{2} \mathrm{H}_{5}\right)_{2}$ & $\mathrm{H}_{2} \mathrm{O}$ & 150 & $10-53$ & 0.54 & $\mathrm{C}_{2} \mathrm{H}_{5} \mathrm{OH}$ & $n-n$ & [76] \\
\hline $\mathrm{ZnO}$ & $\mathrm{In}_{2} \mathrm{O}_{3} \mathrm{NRs}$ & $\mathrm{Zn}\left(\mathrm{C}_{2} \mathrm{H}_{5}\right)_{2}$ & $\mathrm{H}_{2} \mathrm{O}$ & 150 & $5-10$ & - & $\mathrm{H}_{2} \mathrm{~S}$ & $n-n$ & [77] \\
\hline $\mathrm{ZnO}$ & $\mathrm{Nb}_{2} \mathrm{O}_{5} \mathrm{NRs}$ & $\mathrm{Zn}\left(\mathrm{C}_{2} \mathrm{H}_{5}\right)_{2}$ & $\mathrm{H}_{2} \mathrm{O}$ & 150 & $0-63$ & 0.7 & $\mathrm{H}_{2}$ & $\mathrm{n}$ & {$[78]$} \\
\hline $\mathrm{ZnO}$ & $\begin{array}{c}\mathrm{Bi}_{2} \mathrm{O}_{3} \\
\text { nanobelts }\end{array}$ & $\mathrm{Zn}\left(\mathrm{C}_{2} \mathrm{H}_{5}\right)_{2}$ & $\mathrm{H}_{2} \mathrm{O}$ & 150 & 20 & 0.4 & $\mathrm{NO}_{2}$ & $n-n$ & [79] \\
\hline ZnO & $\alpha-\mathrm{Fe}_{2} \mathrm{O}_{3} \mathrm{NRs}$ & $\mathrm{Zn}\left(\mathrm{C}_{2} \mathrm{H}_{5}\right)_{2}$ & $\mathrm{H}_{2} \mathrm{O}$ & 150 & 32 & 0.36 & $\begin{array}{c}\mathrm{C}_{2} \mathrm{H}_{5} \mathrm{OH} ; \\
\mathrm{C}_{3} \mathrm{H}_{7} \mathrm{OH} ; \\
\mathrm{CH}_{3} \mathrm{COCH}_{3} ; \\
\mathrm{C}_{7} \mathrm{H}_{8} ; \mathrm{C}_{6} \mathrm{H}_{6}\end{array}$ & $n-n$ & [80] \\
\hline $\begin{array}{c}\mathrm{ZnO} \text { (w/o Pt } \\
\text { NPs) }\end{array}$ & $\mathrm{SnO}_{2} \mathrm{NWs}$ & $\mathrm{Zn}\left(\mathrm{C}_{2} \mathrm{H}_{5}\right)_{2}$ & $\mathrm{H}_{2} \mathrm{O}$ & 150 & $5-80$ & - & $\begin{array}{c}\mathrm{CO} ; \mathrm{CO}_{2} ; \\
\mathrm{C}_{7} \mathrm{H}_{8} ; \mathrm{C}_{6} \mathrm{H}_{6}\end{array}$ & $n-n$ & [81] \\
\hline $\mathrm{ZnO}$ & Optical fiber & $\mathrm{Zn}\left(\mathrm{C}_{2} \mathrm{H}_{5}\right)_{2}$ & $\mathrm{H}_{2} \mathrm{O}$ & - & $40-220$ & - & $\mathrm{C}_{3} \mathrm{H}_{7} \mathrm{OH}$ & optical & $882]$ \\
\hline $\mathrm{ZnO}$ & PAN fibers & $\mathrm{Zn}\left(\mathrm{C}_{2} \mathrm{H}_{5}\right)_{2}$ & $\mathrm{H}_{2} \mathrm{O}$ & 100 & 20 & 0.2 & $\mathrm{C}_{2} \mathrm{H}_{5} \mathrm{OH}$ & optical & [39d] \\
\hline $\begin{array}{c}\mathrm{ZnO} / \mathrm{TiO}_{2} \\
\text { NTs }\end{array}$ & $\begin{array}{c}\text { ES-PVA fibers } \\
\text { template }\end{array}$ & $\begin{array}{c}\mathrm{Ti}\left(\mathrm{O}^{\mathrm{i}} \mathrm{Pr}\right)_{4} \\
\mathrm{Zn}\left(\mathrm{C}_{2} \mathrm{H}_{5}\right)_{2}\end{array}$ & $\begin{array}{l}\mathrm{H}_{2} \mathrm{O} \\
\mathrm{H}_{2} \mathrm{O} \\
\end{array}$ & 150 & $\begin{array}{c}30 \\
3-70\end{array}$ & $\begin{array}{c}0.03 \\
0.2 \\
\end{array}$ & $\mathrm{CO}, \mathrm{NO}_{2}$ & $n-n$ & {$[48]$} \\
\hline $\mathrm{ZnAl}_{2} \mathrm{O}_{4}$ & ZnO NWs & $\mathrm{Al}\left(\mathrm{CH}_{3}\right)_{3}$ & $\mathrm{H}_{2} \mathrm{O}$ & $\begin{array}{c}115 \\
+ \\
700 \\
\end{array}$ & 5 & - & $\begin{array}{c}\mathrm{CO} ; \mathrm{NO}_{2} ; \mathrm{O}_{2} \\
\mathrm{O}_{3}\end{array}$ & $n-n$ & [83] \\
\hline $\mathrm{Zn}_{2} \mathrm{TiO}_{4}$ & ZnO NWs & $\mathrm{Ti}\left(\mathrm{O}^{\prime} \mathrm{Pr}\right)_{4}$ & $\mathrm{H}_{2} \mathrm{O}$ & $\begin{array}{c}115 \\
+ \\
700 \\
\end{array}$ & 5 & - & $\begin{array}{c}\mathrm{CO} ; \mathrm{NO}_{2} ; \mathrm{O}_{2} ; \\
\mathrm{O}_{3}\end{array}$ & $n-n$ & [83] \\
\hline $\mathrm{TiO}_{2}$ & ZnO NRs & - & - & 250 & 10 & - & $\mathrm{RH} ; \mathrm{NO}_{2}$ & $n-n$ & [84] \\
\hline $\mathrm{TiO}_{2}$ & MWCNTS & $\mathrm{Ti}\left(\mathrm{O}^{\mathrm{i}} \mathrm{Pr}\right)_{4}$ & $\mathrm{CH}_{3} \mathrm{COOH}$ & 200 & $1.5-15$ & 0.06 & $\mathrm{O}_{2} ; \mathrm{NO}_{2}$ & n ou $p-p$ & 855 \\
\hline $\mathrm{Al}_{2} \mathrm{O}_{3}$ & SWCNTS & $\mathrm{Al}\left(\mathrm{CH}_{3}\right)_{3}$ & $\mathrm{H}_{2} \mathrm{O}$ & 150 & 40 & - & $\mathrm{CO}$ & - & [86] \\
\hline $\mathrm{SnO}_{2}$ & $\mathrm{Ga}_{2} \mathrm{O}_{3} \mathrm{NWs}$ & DBTDA & $\mathrm{O}_{2}$ plasma & 100 & $4-15$ & 0.05 & $\begin{array}{c}\mathrm{CO} ; \mathrm{H}_{2} ; \mathrm{NH}_{3} ; \\
\mathrm{C}_{2} \mathrm{H}_{5} \mathrm{OH}\end{array}$ & $n-n$ & [87] \\
\hline $\mathrm{SnO}_{2}$ & MWCNTs & $\mathrm{Sn}\left(\mathrm{O}^{\mathrm{t}} \mathrm{Bu}\right)_{4}$ & $\mathrm{CH}_{3} \mathrm{COOH}$ & 200 & $1.5-15$ & 0.06 & $\mathrm{O}_{2} ; \mathrm{NO}_{2}$ & $n-p$ & $\begin{array}{c}{[13,56 \mathrm{e},} \\
88]\end{array}$ \\
\hline $\mathrm{ZnO}$ & MWCNTs & $\mathrm{Zn}\left(\mathrm{C}_{2} \mathrm{H}_{5}\right)_{2}$ & $\mathrm{H}_{2} \mathrm{O}$ & - & - & - & $\mathrm{NO}_{2}$ & $n-p$ & {$[88]$} \\
\hline $\mathrm{ZnO}$ & MWCNTs & $\mathrm{Zn}\left(\mathrm{C}_{2} \mathrm{H}_{5}\right)_{2}$ & $\mathrm{H}_{2} \mathrm{O}$ & $\begin{array}{c}175 \\
- \\
220 \\
\end{array}$ & $7.74-10.8$ & 0.16 & $\mathrm{CH}_{4} ; \mathrm{RH}$ & & [89] \\
\hline $\mathrm{CuO}$ & $\mathrm{SnO}_{2} \mathrm{NWs}$ & $\begin{array}{c}\mathrm{C}_{14} \mathrm{H}_{32} \mathrm{~N}_{2} \mathrm{O}_{2} \mathrm{C} \\
\mathrm{u}\end{array}$ & $\mathrm{H}_{2} \mathrm{O}$ & 140 & $5-80$ & 0.01 & $\begin{array}{c}\mathrm{NO}_{2} ; \mathrm{C}_{7} \mathrm{H}_{8} ; \\
\mathrm{C}_{6} \mathrm{H}_{6}\end{array}$ & $p-n$ & {$[56 c]$} \\
\hline $\mathrm{Ni}$ & Si NWs & $\mathrm{Ni}(\mathrm{dmamb})_{2}$ & $\mathrm{NH}_{3}$ & 300 & 20 & 0.064 & $\mathrm{Cl}_{2}$ & - & [90] \\
\hline $\mathrm{Pt}$ & $\mathrm{SnO}_{2} \mathrm{NWs}$ & $\mathrm{MeCpPtMe}_{3}$ & $\mathrm{O}_{2}$ & 250 & $2-8.8$ & 0.035 & $\mathrm{C}_{2} \mathrm{H}_{5} \mathrm{OH}$ & $M-n$ & [91] [92] \\
\hline $\mathrm{Pt}$ & graphene & $\mathrm{MeCpPtMe}_{3}$ & $\mathrm{O}_{2}$ & 300 & $10-30$ & 0.03 & $\mathrm{H}_{2}$ & M-p & [93] \\
\hline $\mathrm{TiO}_{2}$ & $\begin{array}{c}\mathrm{TiO}_{2} \text { or } \mathrm{SiO}_{2} \\
\text { nanocolumn }\end{array}$ & $\mathrm{Ti}\left(\mathrm{O}^{\mathrm{i}} \mathrm{Pr}\right)_{4}$ & $\mathrm{O}_{2}$ plasma & 200 & $0.25-4$ & 0.05 & $\mathrm{RH}$ & capa & [94] \\
\hline $\mathrm{Al}_{2} \mathrm{O}_{3}$ & $\begin{array}{l}\text { Microring } \\
\text { resonators }\end{array}$ & $\mathrm{Al}\left(\mathrm{CH}_{3}\right)_{3}$ & $\mathrm{H}_{2} \mathrm{O}$ & 200 & - & - & $\mathrm{NH}_{3}$ & optical & [95] \\
\hline $\mathrm{Al}_{2} \mathrm{O}_{3}$ & Butterfly wing & $\mathrm{Al}\left(\mathrm{CH}_{3}\right)_{3}$ & $\mathrm{H}_{2} \mathrm{O}$ & 100 & $5-40$ & - & $\begin{array}{c}\mathrm{C}_{2} \mathrm{H}_{5} \mathrm{OH} ; \\
\mathrm{CH}_{3} \mathrm{COCH}_{3} ; \\
\mathrm{H}_{2} \mathrm{O} ; \mathrm{C}_{7} \mathrm{H}_{8} ; \\
\mathrm{CH}_{3} \mathrm{COOH} ; \\
\mathrm{CHCl}_{3}\end{array}$ & optical & [96] \\
\hline
\end{tabular}

\section{$\underline{n-n \text { heterojunctions }}$}

Sensing materials made of $n$-type semiconductor cores and shells are the most widely investigated heterostructures. Most of the structures reported in the literature are based on ALD of n-type ZnO thin films deposited onto n-type metal oxide nanostructures, such as nanowires (NWs), nanorods (NRs) and 
fibers. Core-shell materials have been fabricated by combining ALD with either electrospinning (ES) ${ }^{[48,}$ 56b, 62-63, 67] thermal evaporation, ${ }^{[56 f, 64-65,68,74-76,79,87]}$ vapor-liquid-solid (VLS) ${ }^{[56 a, 81]}$ or hydrothermal $^{[66,84]}$ synthesis. An enhancement of sensitivity has been noted when a CS material was used instead of a pure material. For instance, ethanol detection was studied using either $\mathrm{TiO}_{2}$-core/ZnO-shell or pure $\mathrm{TiO}_{2} \mathrm{NRs}$. A continuous and uniform $20 \mathrm{~nm}$ thick ZnO ALD film was deposited onto the core surface. The TEM images and EDS line profile clearly demonstrate the CS structure (Figure 5). The improved response recorded could be explained by two effects: i) the higher basicity and the catalytic property of the $\mathrm{ZnO}$ surface that permit a higher adsorption and dehydrogenation of ethanol compared to $\mathrm{TiO}_{2}$ and $\mathrm{ii}$ ) the presence of a heterojunction that creates a potential barrier between the two materials in addition to the surface depletion region. ${ }^{[66]}$ By comparing the response towards ethanol of various 1D CS and pure $\mathrm{ZnO}$ and $\mathrm{TiO}_{2}$ nanostructures, the authors highlight the response improvement of the CS compared to sensitivity of the single nanomaterial-based sensors.

A device made of electrospun tin dioxide nanofibers coated with a $10 \mathrm{~nm}$-thick $\mathrm{ZnO}$ film showed a sharp increase of sensitivity toward $\mathrm{CO}$ compared to pure $\mathrm{ZnO}$ and $\mathrm{SnO}_{2}$ nanofibers. The sensitivity enhancement is attributed to the full depletion of the $\mathrm{ZnO}$ shell due to surface adsorption and the presence of the heterojunction. Indeed, at both interfaces, i.e. at the $\mathrm{ZnO}$ surface interacting with the adsorbed species and at the heterojunction, band bending occurs. The calculated widths of the depletion region, ranging from 69 to $53 \mathrm{~nm}$, respectively, are larger than the shell size, which is thus fully depleted and contributes entirely to the sensing mechanism. ${ }^{[63]}$ One should note that the calculated depletion widths are nearly one order higher than those usually reported. The effect of the thickness of coating was not studied in this paper.

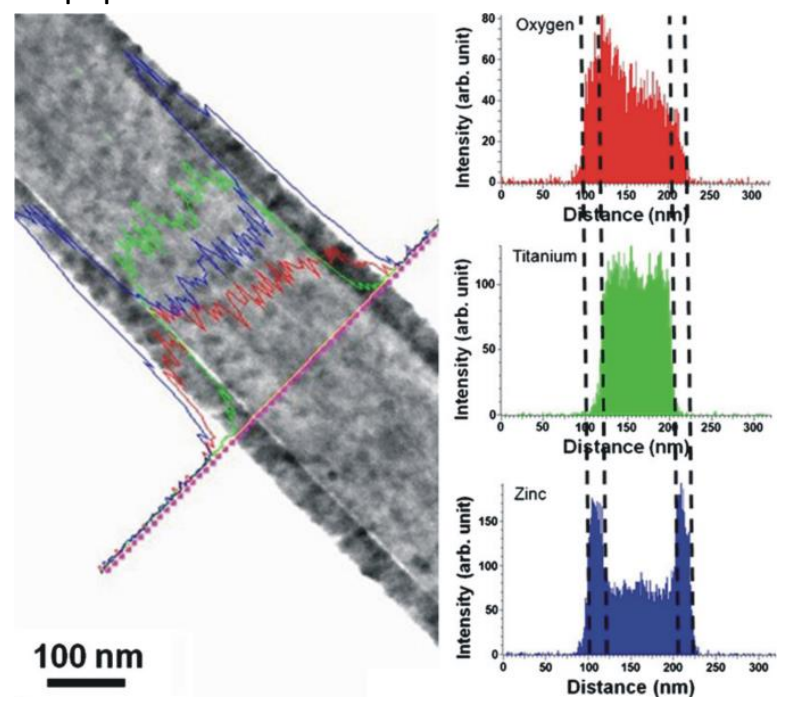

Figure 5. TEM image with EDS line scanning concentration profiles of the $\mathrm{TiO}_{2}$-core/ZnO-shell nanorods. Reproduced with permission from Ref. ${ }^{[66]}$

Katoch et al. ${ }^{[56 \mathrm{~b}]}$ investigated the influence of the thickness of $\mathrm{ZnO}$ shell deposited on electrospun $\mathrm{SnO}_{2}$ fibers. The core-shell structures revealed to be effective in detecting reducing gases only. An increase of sensitivity was noticed toward $\mathrm{CO}$ compared to pristine $\mathrm{SnO}_{2}$. The optimal shell thickness was found to be $20 \mathrm{~nm}$, corresponding to the Debye length of $\mathrm{ZnO}$ at the operating temperature of $300{ }^{\circ} \mathrm{C}$. On the other hand, the presence of the $\mathrm{ZnO} / \mathrm{SnO}_{2}$ interface weakened the sensitivity toward oxidizing gases, 
such as $\mathrm{NO}_{2}$. These phenomena were attributed to a radial modulation of the electron depleted shell layer in the core-shell material. When exposed to air, the adsorbed oxygen extracts electron from the $\mathrm{ZnO}$ shell. When its thickness is in the range of the Debye length, the shell is fully depleted and in turn depletes the region close to the heterojunction with electrons migrating from the core to the shell. An exposure to $\mathrm{CO}$ releases electrons into the shell, which passes from entirely to partially depleted leading to an increase of the conductivity. Instead, when exposed to an oxidizing analyte such as $\mathrm{NO}_{2}$, nearly no electrons are available for its reduction leading to almost no conductivity change of the device. The mechanism is schematized in Figure $6 \mathbf{a , b}$. The $\mathrm{SnO}_{2}$ electrospun fibers cores, which are uniformly and conformally coated with $\mathrm{ZnO}$ ALD, show grain boundaries (Figure $6 c$,d). To avoid the presence of the grain boundaries in the $\mathrm{SnO}_{2}$ core, which complicate mechanistic studies, in a following work single crystalline $\mathrm{SnO}_{2}$ nanowires were grown by vapor-liquid-solid and coated by $\mathrm{ZnO}$ ALD. An improved ntype response to reducing gases was demonstrated, with an optimal shell thickness of $40 \mathrm{~nm}$, while lower sensitivity occurred toward oxidizing gases compared to the pure component counterparts, as depicted in the Figure 6e. Unlike the work on electrospun $\mathrm{SnO}_{2} / \mathrm{ALD}-\mathrm{ZnO}$ core/shell nanofibers, the sensing mechanism is not only attributed to a radial modulation, but to a dual mechanism that involves radial modulation of the electron depleted layer and electric field smearing effect (Figure 6f). The transition from fully to partially electron depleted layer is not enough to explain the "bell-shaped" sensing behavior as the function of the shell thickness. Indeed, the sensitivity should increase until the shell becomes thicker than the Debye length. It was postulated that the electron transport can occur either in both the shell and the core (when the shell thickness is $<\lambda_{D}$ ) leading to an increase of the resistance modulation as a part of the electron transport smears into the core, or it remains confined into the shell only when its thickness is larger than $\lambda_{D}$. In the latter case the response is attributed only to the radial modulation. ${ }^{[56 a]}$ 

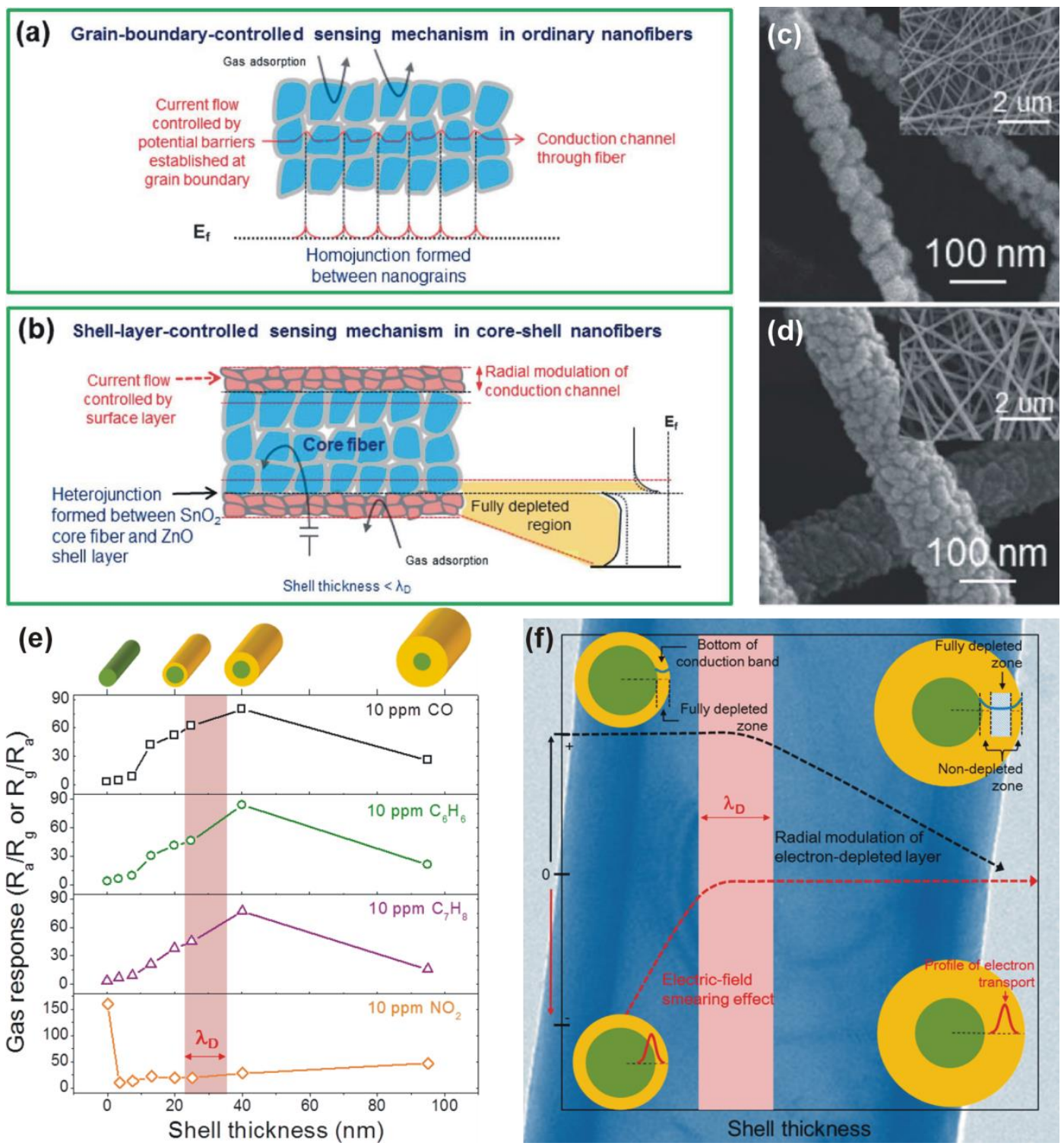

Figure 6. Scheme of the sensing mechanism involved (a) in normal and (b) in core/shell nanofibers. SEM images of (c) bare and (d) coated with $160 \mathrm{ZnO}$ ALD cycles $\mathrm{SnO}_{2}$ electrospun fibers. Reproduced with permission from Ref. ${ }^{[56 b]}$ (e) responses of single crystalline $\mathrm{SnO}_{2}$-core/ZnO-shell nanowires to different target gases as a function of the shell thickness. (f) dual sensing mechanism of core-shell nanowires based sensor, combining radial modulation and electric-field smearing effect. Reproduced with permission from Ref. ${ }^{[56 a]}$

The contribution of $n-n$ heterojunctions in CS materials, in particular when the shell thickness is in the range of the electron depletion region width, on the sensitivity towards reducing over oxidizing gases has been demonstrated. However, it is not yet fully understood why $n-n$ heterojunctions favor the detection of reducing gases in $\mathrm{SnO}_{2} / \mathrm{ZnO} C S$ materials. Indeed, an enhanced response towards oxidizing gases was reported with other metal oxide/ZnO CS nanostructures. For example, thermal evaporated $\mathrm{Ga}_{2} \mathrm{O}_{3}$ nanorods coated with a $13 \mathrm{~nm}$ thick ALD single crystalline $\mathrm{ZnO}$ film presented a 692 times higher response to $100 \mathrm{ppm} \mathrm{NO}$ at $300{ }^{\circ} \mathrm{C}$ compared to pristine $\mathrm{Ga}_{2} \mathrm{O}_{3}$ nanorods. The modulation of the 
electron transport by the heterojunction was highlighted and it was suggested that the effective barrier at the $\mathrm{Ga}_{2} \mathrm{O}_{3} / \mathrm{ZnO}$ interface adjusts as a function of the surface depletion facilitating or restraining the charge carrier transport through the interface. Another interesting point to note is the respective increase and decrease of the response and recovery time when the $\mathrm{ZnO}$ shell is present. Even though this phenomenon is not yet well understood, the authors hypothesized a different order and transport kinetic of the reaction of the carrier in the depletion and the heterojunction region, respectively. During $\mathrm{NO}_{2}$ exposure, electron flows from the core to the shell and to the adsorbed species, while inversely upon its removal. Due to the different barrier height, one transport direction might be faster than the other. ${ }^{[56 f]}$

UV-enhanced $\mathrm{NO}_{2}$ sensing was demonstrated at room temperature using $\mathrm{SnO}_{2} / \mathrm{ZnO}$ CS nanostructrures. UV light exposure increases the number of electrons available to react with $\mathrm{NO}_{2}$ by formation of holeelectron pairs, which react with adsorbed oxygen diminishing then the surface depletion layer width. The heterojunction modulates the charge carrier transport increasing the resistance variation upon gas exposure and removal. ${ }^{[65]}$

A sensor toward reducing gases based on double layer hollow fibers (DLHFs) was fabricated using a sacrificial polymer electrospun fiber, which was coated with $\mathrm{TiO}_{2}$ and $\mathrm{ZnO}$ layers using ALD. Removal of the polymer by heat treatment lead to an inner titania tube of $30 \mathrm{~nm}$ wall thick and an outer zinc oxide shell. ${ }^{[48]}$ By varying the number of cycles the thickness of the outer oxide was controlled (Figure 7). An improved and a lower response of the DLHF-based sensor toward $\mathrm{CO}$ and $\mathrm{NO}_{2}$, respectively, was observed as compared to the response of $\mathrm{ZnO}$ and $\mathrm{TiO}_{2}$ hollow fibers. Furthermore, a $20 \mathrm{~nm}$ thick $\mathrm{ZnO}$ shell appeared optimal for sensing reducing gas and the most unfavorable for the detection of the oxidizing species. A "bell-shape" relation between sensitivity and shell thickness is observed, with a maximum when the shell thickness is in the range of the Debye length (Figure $\mathbf{7 i , j}$ ). Exposure to CO leads to a resistance decrease of the sensor, which is a typical for n-type semiconductors. When the ZnO layer is thinner or equal than $\lambda_{D}$, the metal oxide is fully depleted under air, and it turns into partially electron depleted upon $\mathrm{CO}$ exposure. The target gas reacts with adsorbed oxygen species to form $\mathrm{CO}_{2}$; the captured electrons are then released into the sensing layer. The different sensitivity between hollow and double layer hollow fibers is explained by the presence of the $\mathrm{TiO}_{2} / \mathrm{ZnO}$ heterojunction that produce a $4 \mathrm{~nm}$ wide space-charge region, in addition to the depleted surface. According to the energy band structure, electrons flow from the outer $\mathrm{ZnO}$ shell to the inner $\mathrm{TiO}_{2}$ core, leading to a space charge region larger than $\lambda_{D}$. The $\mathrm{ZnO}$ layer in DLHFs is thus more electron-depleted than that in a pure $\mathrm{ZnO}$ hollow fiber with similar wall thickness. Furthermore, it should be noted that when the $\mathrm{TiO}_{2}$ core is also fully electron depleted, it also contributes to the gas detection because the gaseous species can diffuse inside the inner pores. The inhibited response to oxidizing gas can be explained by the lack of electrons available to interact with the incoming $\mathrm{NO}_{2}$ at both inner $\left(\mathrm{TiO}_{2}\right)$ and outer $(\mathrm{ZnO})$ surfaces. ${ }^{[48]}$ 

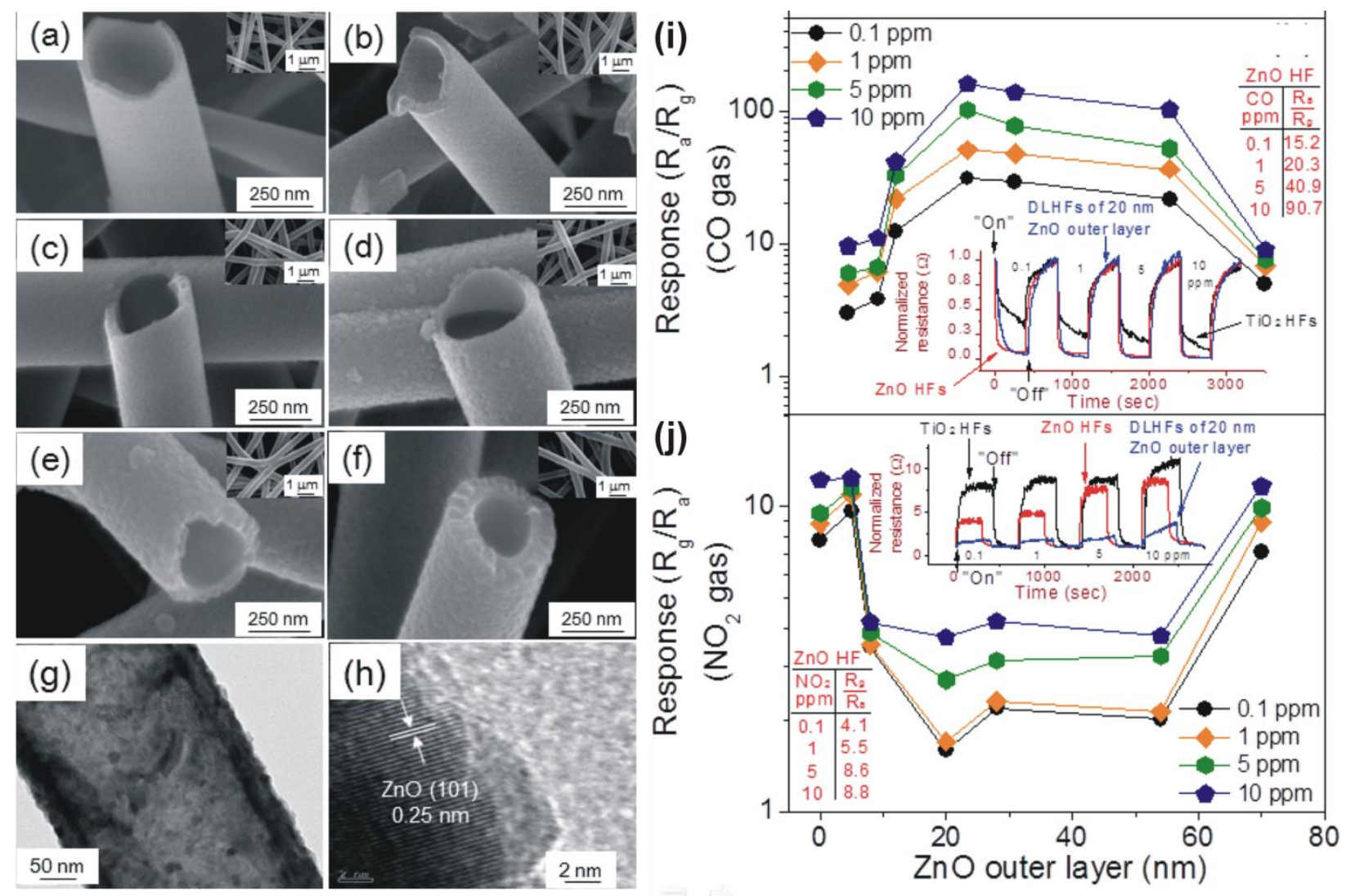

Figure 7. SEM images of (a) $\mathrm{TiO}_{2}$ hollow fibers and $\mathrm{TiO}_{2} / \mathrm{ZnO}$ double layer hollow fibers prepared with (b) 20, (c), 50, (d) 90, (e) 220 and (f) $350 \mathrm{ZnO}$ ALD cycles. (g) TEM image of $\mathrm{TiO}_{2} / \mathrm{ZnO}$ DLHF with $8 \mathrm{~nm}$ thick $\mathrm{ZnO}$ layer and (h) high magnification TEM image recorded on the $\mathrm{ZnO}$ region. Responses of the DLHF based sensor toward exposure of (i) $\mathrm{CO}$ and (j) $\mathrm{NO}_{2}$ as a function of the $\mathrm{ZnO}$ thickness. Reproduced with permission from Ref. ${ }^{[48]}$

\section{p-n or $n-p$ heterojunctions}

In addition to $n-n$ heterojunction core-shell nanostructures, which are the most common heterojunctions elaborated by ALD, few reports focus on a CS $p-n$ or $n-p$ heterojunctions. Especially $p$ $\mathrm{CuO}$ core/n-ZnO shell, $\mathrm{n}-\mathrm{SnO}_{2}$ core $/ \mathrm{p}-\mathrm{Cu}_{2} \mathrm{O}$ shell and $\mathrm{p}$-Carbon core $/ \mathrm{n}-\mathrm{MO}_{\mathrm{x}}$ shell heterostructures have been reported. ${ }^{[13,56 c, 56 d, 57 a, 59-61,73,85-86,88]}$

CuO electrospun fibers were coated with $\mathrm{ZnO} A L D$ at $150{ }^{\circ} \mathrm{C}$ and their sensing properties toward toluene and $\mathrm{CO}$ were investigated. Conformal polycrystalline shells were obtained on the NWs (Figure 8a) when the coating was thicker than $5 \mathrm{~nm}$. CS fibers with only a partial $\mathrm{ZnO}$ coverage showed a $\mathrm{p}$-type response to $\mathrm{CO}$, similar to bare $\mathrm{CuO}$ fibers, whereas when a continuous coating is formed a n-type response was observed. The sensor with a $16 \mathrm{~nm}$-thick $\mathrm{ZnO}$ shell showed the highest sensitivity, which was comparable to that obtained with n-n CS structures. ${ }^{[73]} \mathrm{CuO}$ nanowires were also coated with ZnO ALD. The CS NWs exhibited a reversible decrease in resistance upon gas exposure, typical of n-type semiconductor (Figure $\mathbf{8 b}$ ). The highest response was reached for a $36 \mathrm{~nm}$-thick $\mathrm{ZnO}$ shell which was higher to that of the isolated components (Figure 8c). ${ }^{[56 \mathrm{~d}]}$ It should be pointed out that the optimal shell 
thickness was in the range of the Debye length ( $22 \mathrm{~nm}$ ). Moreover, only a poor sensitivity was reported to oxidizing gases such as $\mathrm{NO}_{2}{ }^{[72]}$ The $\mathrm{p}$-n junction was made responsible for the improved sensing properties toward reducing gases and degraded response to oxidizing gases. An equivalent sensing mechanism than that of $n-n$ junction was proposed, namely a radial modulation of the conductive channel by adsorption and desorption of the surrounding gases. ${ }^{[56 \mathrm{~d}]}$

Carbon nanotubes (CNTs) coated with metal oxides by ALD have been also investigated as sensing layers. Offering a high surface area, good thermal and electrical conductivity and mechanical as well as chemical stability, CNTs are ideally suited as support for a second material that can be deposited onto their surface either as particles or as a continuous thin film. ${ }^{[97]}$ Combining semiconductor oxides with a conductive support will permit to reduce the overall resistance of the sensitive layer. Metal oxidecoated single-wall and multi-walls CNTs have been reported for $\mathrm{CO},{ }^{[86]} \mathrm{O}_{2}$ and $\mathrm{NO}_{2}$ detection. ${ }^{[13,57 a, 85]}$ Conformal and homogeneous coating of the inner and outer surface of CNTs was demonstrated by atomic layer deposition (Figure 8d,e). In particular, $\mathrm{V}_{2} \mathrm{O}_{4^{-}}, \mathrm{TiO}_{2^{-}}, \mathrm{ZnO}$ - and $\mathrm{SnO}_{2}-\mathrm{ALD}$ coated nanotubes were tested as active component in gas-sensing devices. ${ }^{[13,57 a, 85,88]}$ Response to $\mathrm{O}_{2}$ and $\mathrm{NO}_{2}$ at different concentrations and sensor temperature were investigated. No modification of the response (type and height) to $\mathrm{NO}_{2}$ was observed using $\mathrm{ZnO}$-coated CNTs, while improved sensitivity and change from $\mathrm{p}$ - to n-type response (for pristine- and metal oxide coated-CNTs, respectively) were observed with $\mathrm{V}_{2} \mathrm{O}_{4}$ - and $\mathrm{SnO}_{2}$-coatings. The response change was attributed to the formation of a $\mathrm{p}$ - $\mathrm{n}$ heterojunction between the $p$-type carbon substrate and n-type metal oxide thin film. ${ }^{[13,57 a]}$ The synergy, caused by the interaction of the film and the support, enables the detection of sub-ppm concentrations of $\mathrm{NO}_{2}$ at low temperature $\left(150^{\circ} \mathrm{C}\right)$ and in just few seconds with a CNTs/SnO -based sensor (Figure 8f). ${ }^{[13]}$ This effect is strongly influenced by the thickness, morphology and microstructure of the coating, as pointed out by a comparative study on $\mathrm{SnO}_{2}$ /carbon heterostructures fabricated by different approaches. ${ }^{[56 e]}$ When the thickness of the metal oxide coating is comparable to the width of the depletion regions formed at both interfaces, gas $/ \mathrm{MO}_{\mathrm{x}}$ and $\mathrm{MO}_{\mathrm{x}} /$ carbon, the entire film is electron-depleted and participates to the detection (modulation of the resistance) leading to a maximum in the sensitivity. In addition to the $\mathrm{MO}_{\mathrm{x}} /$ carbon junction, other junctions exist such that carbon- $\mathrm{MO}_{\mathrm{x}} / \mathrm{MO}_{\mathrm{x}}$-carbon (between two coated tubes) and carbon-carbon (between two uncoated CNTs) and influence the response to the target gas. It has been shown that carbon-carbon junctions have to be avoided, while the carbon- $\mathrm{MO}_{\mathrm{x}} / \mathrm{MO}_{\mathrm{x}}$-carbon junctions are essential for response enhancement. Furthermore it is worth noting that generally the response is of the same type that of the metal oxide (n-type for $\mathrm{V}_{2} \mathrm{O}_{4}, \mathrm{SnO}_{2}$ ). However, a p-type response was noted for $\mathrm{TiO}_{2} / \mathrm{CNTS}$. To explain this phenomenon, hypotheses have been formulated, as the response might be determined by the nature of the carbon- $\mathrm{MO}_{\mathrm{x}} / \mathrm{MO}_{\mathrm{x}}$-carbon homojunction. ${ }^{\left[{ }^{85]}\right.}$ On the other hand, deposition of p-type $\mathrm{TiO}_{2}$ film cannot also be excluded. Oxygen defective $\mathrm{TiO}_{2}$ films deposited from tetrakis(dimethylamido) titanium and water, have been reported to exhibit p-type conductivity ${ }^{[98]}$ Finally, a transition from $\mathrm{p}$ - to $\mathrm{n}$-type response with the operating temperature was observed in the case of $\mathrm{ZnO}$-coated graphene heterostructures and attributed to a change in nature and concentration of charge carriers. ${ }^{[61]}$ 

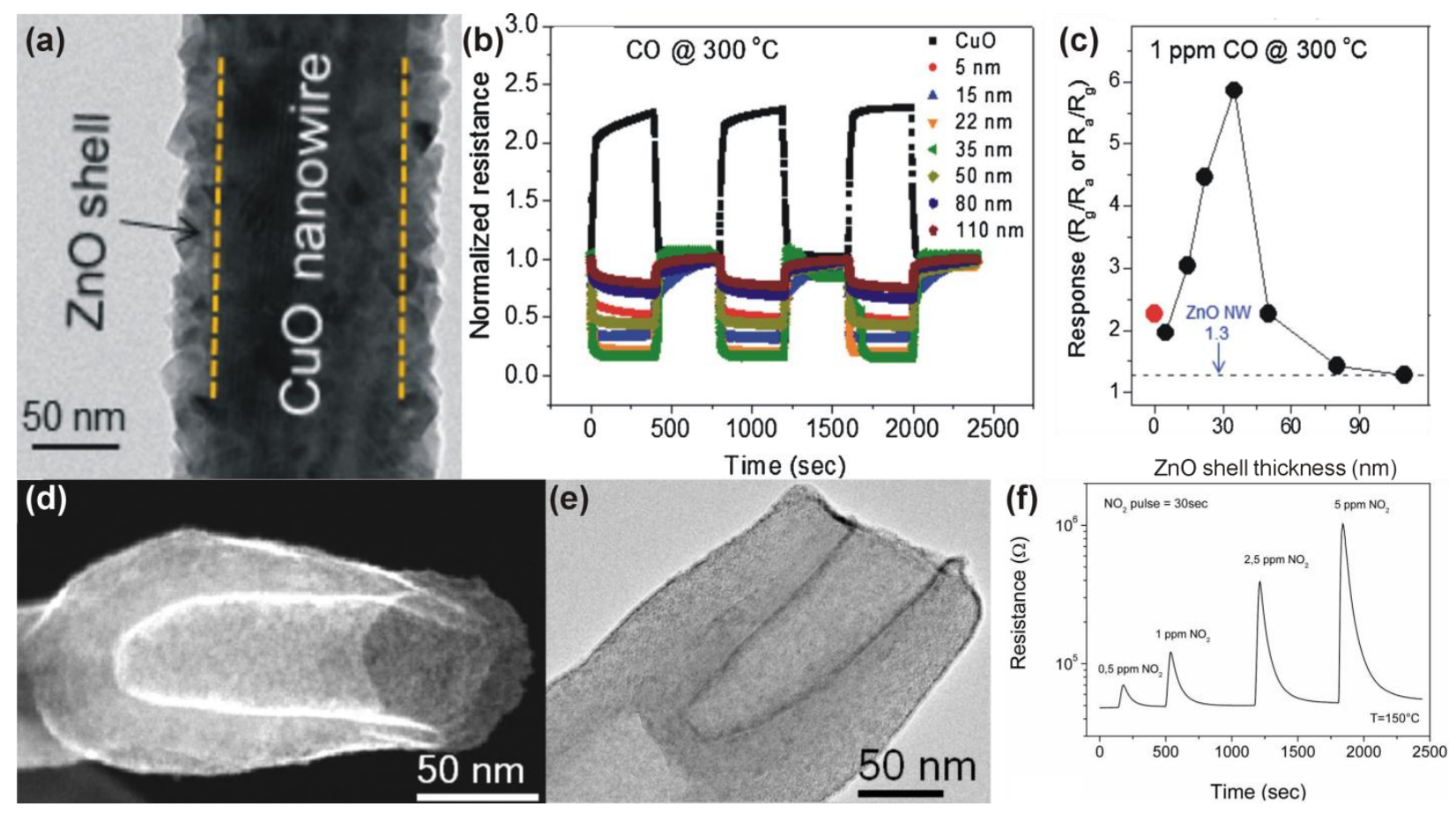

Figure 8. a) TEM image of $\mathrm{ZnO}$-coated $\mathrm{CuO}$ nanowire, b) resistance variation of $\mathrm{CuO}$ and $\mathrm{CuO} / \mathrm{ZnO} \mathrm{NWs}$ and c) their response as a function of the shell thickness toward $\mathrm{CO}$ at $300{ }^{\circ} \mathrm{C}$. Reproduced with permission from Ref. ${ }^{[56 d]}$ d) Dark field STEM image recorded and a high resolution TEM image e) recorded from a bamboo like CNT reveal the presence of a thin layer of $\mathrm{SnO}_{2}$ on the inner and outer surface of the final compartment. f) Transient response of the sensor made of $3.0 \mathrm{~nm} \mathrm{SnO}{ }_{2}$-coated CNTs, operating at $150{ }^{\circ} \mathrm{C}$, exposed to $0.5-5 \mathrm{ppm}$ of $\mathrm{NO}_{2}$ for a period of $30 \mathrm{~s}$. Reproduced with permission from Ref. $^{[13]}$

Finally, Kim et al. ${ }^{[56 c]}$ reported a sensor based on n-core/p-shell structures by ALD. $\mathrm{Cu}_{2} \mathrm{O}$ thin film where deposited at $150{ }^{\circ} \mathrm{C}$ onto $\mathrm{SnO}_{2} \mathrm{NWs}$ from bis(1-dimethylamino-26methyl-2-butoxy) copper and water as metal and oxygen sources, respectively. It should be noted that the $\mathrm{SnO}_{2} \mathrm{NWs}$ produced by VLS exhibit and entangled morphology that allows for a continuous electrical pathway within the networked $\mathrm{SnO}_{2}$ NWs film (Figure 9e). Conformal and continuous well-crystalline coatings were formed at the NWs surface, as shown in (Figure 9f). The sensing capabilities of the heterostructures, with various shell thicknesses in the range of 5-80 nm, were tested toward two reducing and one oxidizing gases, toluene, benzene and $\mathrm{NO}_{2}$, respectively. Contrarily to the pure $\mathrm{SnO}_{2} \mathrm{NWs}$-based sensing layer, $\mathrm{SnO}_{2} / \mathrm{Cu}_{2} \mathrm{O}$ nanostructures showed an increase (decrease) of resistivity upon exposure of toluene or benzene $\left(\mathrm{NO}_{2}\right)$, as expected for a p-type semiconductor. The sensitivity to reducing gases was improved, whereas a decrease occurred for oxidizing gases. These findings are explained by the presence of two distinct space charge regions: one with holes accumulation at the $\mathrm{Cu}_{2} \mathrm{O}$ surface and one with holes deficiency at the $\mathrm{SnO}_{2} / \mathrm{Cu}_{2} \mathrm{O}$ heterojunction (Figure 9a-d). When the shell thickness is smaller or equal to $\lambda_{D}$, the hole accumulation region expand to the full $\mathrm{Cu}_{2} \mathrm{O}$ layer when exposed to air, whereas intrinsic hole concentration is observed upon exposure to a reducing gas. The depletion layer at the $\mathrm{SnO}_{2} / \mathrm{Cu}_{2} \mathrm{O}$ interface remains unaffected and the whole resistance of the sensor increases. On the other hand, a 
surface reaction with an oxidizing species would require extracting more electrons from an already fullydepleted shell, moreover the expansion of the space charge region is blocked by the heterojunction leading to a lower resistivity change and therefore to a lower sensitivity to $\mathrm{NO}_{2} \cdot{ }^{\left[{ }^{[6 c]}\right]}$

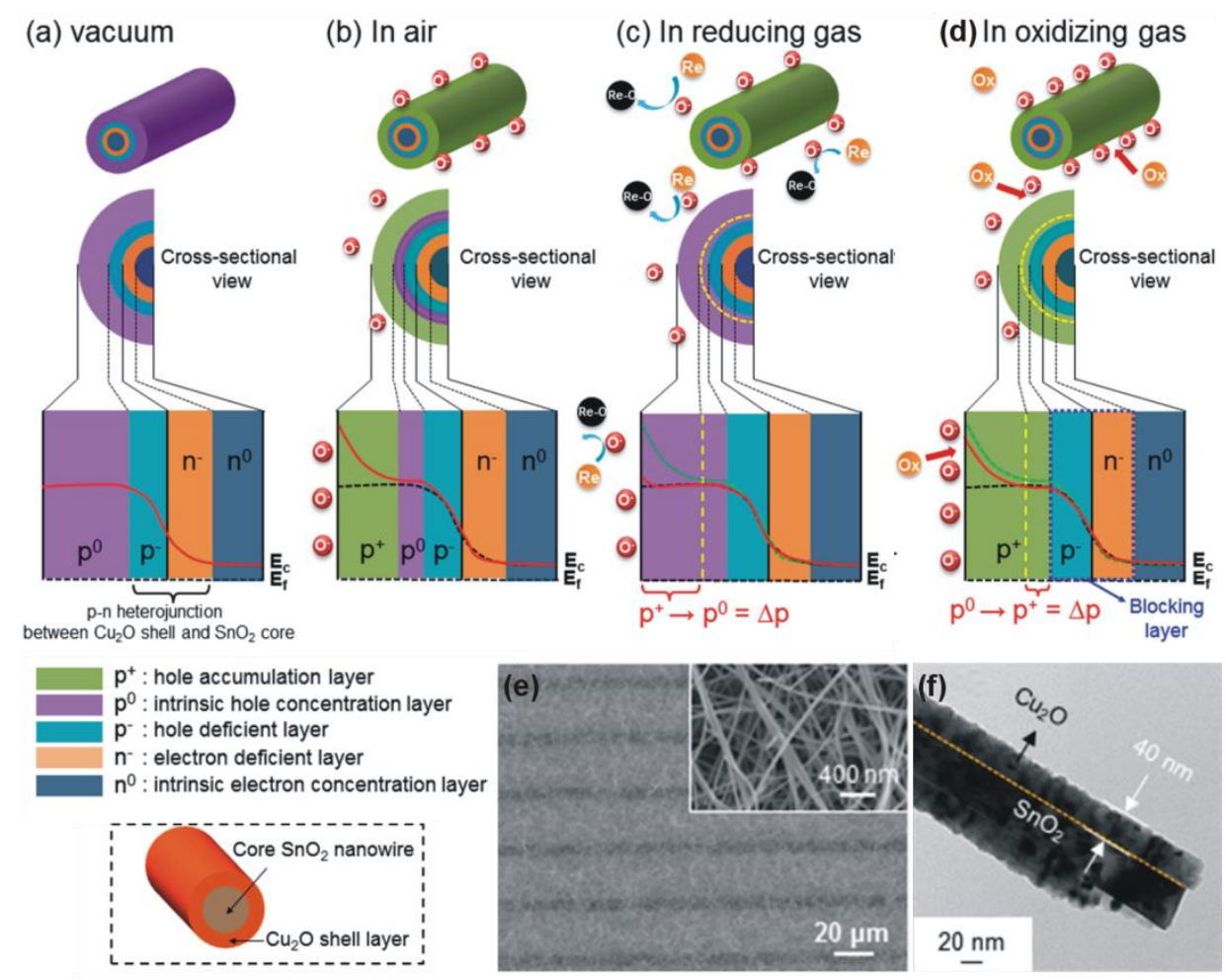

Figure 9. Illustration of the sensing mechanism when using a $n$-core/p-shell based sensor. Electronic structure in: (a) in vacuum, (b) in air and (c) in reducing gases, and (d) in oxidizing gases. (e) SEM images of the entangled $\mathrm{SnO}_{2} \mathrm{NWs}$ grown on the interdigitated electrodes, in inset the corresponding high magnification SEM image. (f) TEM image of $\mathrm{SnO}_{2} / 40 \mathrm{~nm} \mathrm{Cu}_{2} \mathrm{O}$ NWs. Reproduced with permission from Ref. $^{[56 c]}$

\section{Metal-semiconductor heterojunctions}

Metal particles deposited on either metal oxide or carbon nanostructures have been considered for gas sensing applications. ${ }^{[99]}$ ALD of platinum nanoparticles can be carried out from trimethyl(methylcyclopentadienyl)platinum(IV) and dioxygen. ${ }^{[91-93]}$ For example, a hydrogen sensor was fabricated by selectively deposit Pt NPs by ALD on graphene line defects. ${ }^{[93]}$ The selective ALD is made possible by the presence of anchoring sites, onto which the platinum can nucleate, corresponding to the defects. Indeed, due to the high degree of graphitization, a nucleation delay and/or an island growth mode or even an absence of ALD growth, is observed on CNTs and graphene without surface functionalization. ${ }^{[100]}$ In this particular example, a preferential growth along the grain boundaries occurred leading to the formation of a linear decoration. The presence or absence of interconnection between NPs depends on the number of ALD cycles. When the latter is sufficient, coalescence between particles occurs leading to the formation of continuous chain (Figure 10). After $1000 \mathrm{Pt}$ cycles, due to the coalescence of the platinum islands, a decrease of the resistance of the device is noticed. The 
response of the sensor toward dihydrogen was improved in the presence of the interconnected platinum particles. This behavior was explained by the catalytic activity of platinum towards the dissociation of $\mathrm{H}_{2}$ that lead to an electron transfer from platinum to graphene reducing the number of positive charge carriers, and by the peculiar Pt-decoration of the graphene grain boundaries. ${ }^{[93]}$

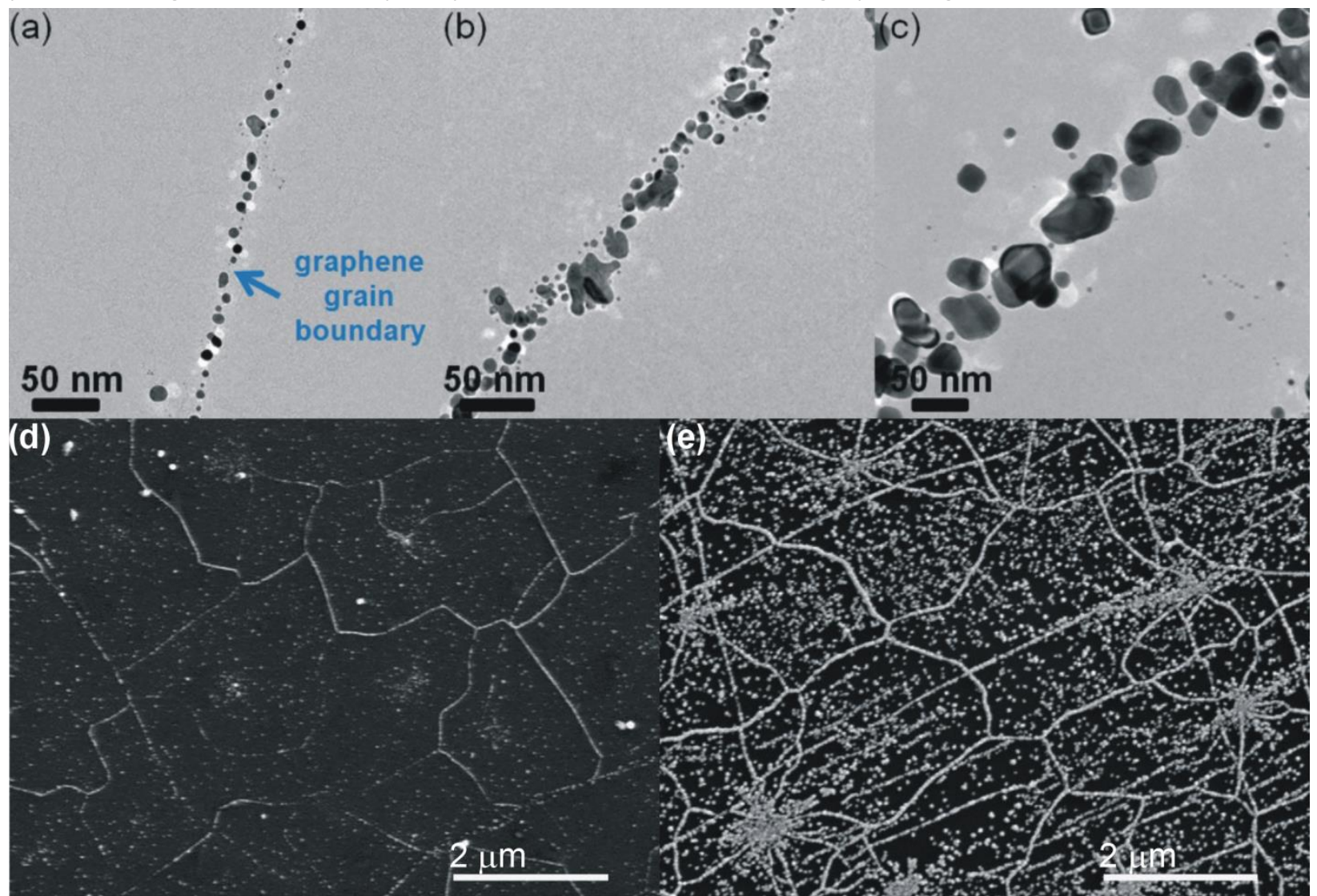

Figure 10. TEM images of Pt nanoparticles grown along a graphene boundaries after (a) 300, (b) 500 and (c) 1000 ALD cycles. SEM images of graphene on glass substrate coated with (d) 500 and (e) 1000 ALD cycles. Reproduced with permission from Ref. $^{[93]}$

An ethanol sensor based on Pt-decorated $\mathrm{SnO}_{2} \mathrm{NWs}$ was fabricated by VLS growth of single crystalline tin dioxide nanostructures which were decorated with platinum particles by ALD at $250{ }^{\circ} \mathrm{C}$. Island growth was first observed and coalescence leading to granular film occurred after 250 cycles (Figure 11a-f). An increase of sensitivity toward ethanol was noticed with the increase of the number of ALD cycles up to 200 cycles, followed by a decrease from 250 ALD cycles. The observed enhancement is explained by the catalytic effect of Pt and by the formation of local Schottky barriers. Having different oxidation states upon ethanol and air exposure, platinum NPs modulate the metal- $\mathrm{SnO}_{2}$ barrier, which plays role of nano-signal amplifiers (Figure 11g). ${ }^{\text {[92] }}$

Metal oxides nanostructures fabricated by ALD were also decorated with metal particles, from wet impregnation processes or attachment of pre-formed nanoparticles. For instance, $\boldsymbol{v}$-ray radiolysis was used to functionalize $\mathrm{SnO}_{2}$-core/ALD ZnO-shell nanowires with Pt NPs. ${ }^{[81]}$ The Pt-CS NWs enabled trace detection of toluene vapor, showing unprecedented sensitivity to $100 \mathrm{ppb}$. On the one hand, the coreshell structure led to improved response, due to presence of the $n-n$ heterojunction. On the other hand, 
Pt-decoration improved the response, due to its catalytic effect and its electronic sensitization that induced electron transport from $\mathrm{ZnO}$ to $\mathrm{Pt}$ via metal-semiconductor heterojunction. The depletion layer of $\mathrm{ZnO}$ is then expanded, driving a shift of maximum sensitivity toward a thicker shell. It is worth noting that the sensor displayed a much higher response toward toluene compared to other gases, such as $\mathrm{CO}$, $\mathrm{CO}_{2}$ and benzene. The selectivity is attributed to a higher catalytic activity of Pt to toluene than to the other reducing gases tested. ${ }^{[81]}$ Recently, Dobrokhtov et al. ${ }^{[69,101]}$ fabricated an electronic nose that enables trace detection of flammable and explosive vapor. The device was composed of 5 chemiresistive sensors coupled with a pattern recognition system. $\mathrm{SiO}_{2}$ nanosprings were coated with ALD ZnO (Figure $11 \mathrm{~h}, \mathrm{i})$ followed by decoration with different metal NPs ( $\mathrm{Pt}, \mathrm{Pd}, \mathrm{Au}, \mathrm{Ni}, \mathrm{Co}$ ). Because of their catalytic properties and of the Schottky junction at the M-ZnO interface, each metal confers to the sensor a specific response signature toward the tested gases and concentrations, which is separated and discriminated by linear discriminant analysis. Individual cross-sensitivity was then overcome using multi sensor response, allowing sensing ppm of acetone, ethanol, toluene, as well as ppb of trinitrotoluene and triacetone triperoxide. 

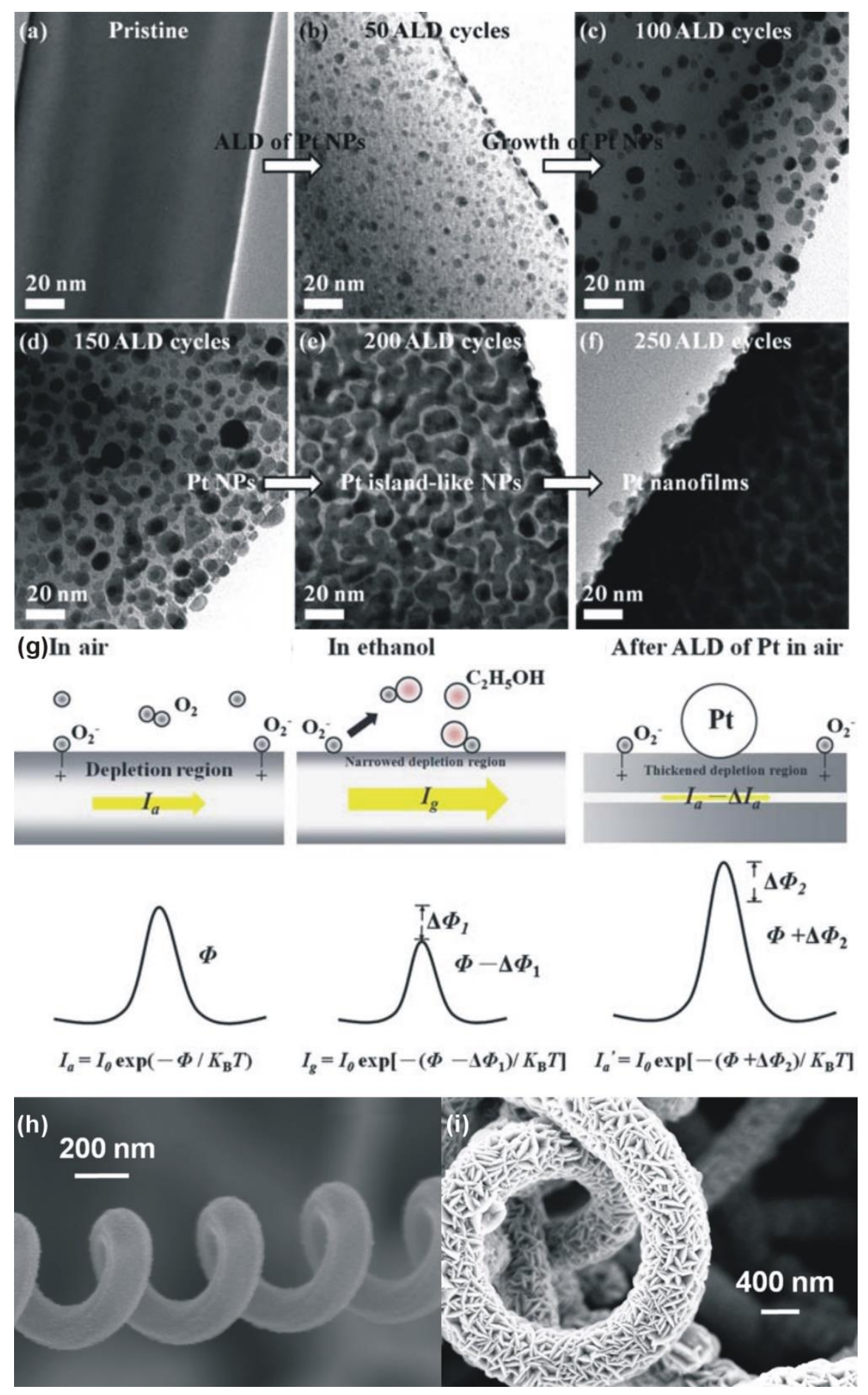

Figure 11. TEM images of (a) bare and (b-f) ALD ZnO coated $\mathrm{SnO}_{2}$ nanowires. Increase of the Pt NPs size is noted with the number of cycles until coalescence of the $(d)$ isolated particles leading to (e) island-like NPs and then to (f) continuous film. (g) scheme of the sensing mechanism involved with and without Pt decoration. Reproduced with permission from Ref. ${ }^{[92]} \mathrm{SEM}$ images of (h) pure and (i) $\mathrm{ZnO}$ coated $\mathrm{SiO}_{2}$ nanospring. Reproduced with permission from Ref. ${ }^{[69 b]}$ 
Several types of heterojunctions have been investigated in materials for gas sensors applications. An improved response, compared to that of the isolated components, in particular toward reducing gases, was observed independently of the type of heterojunction. The existence of an optimal shell thickness, which is in the range of the Debye length, was highlighted in most of the studies. This phenomenon is attributed to a completely electron depleted layer maximizing the volume of the material contributing to the resistance change and the sensing. The sensing mechanisms proposed for heterostructured resistive gas sensors are similar for both $n-n$ and $p-n$ junctions. The improvement of the response is due to the presence of the core/shell junction that creates band bending and an electron depletion layer at the interface between the two materials, in addition to the one existing at the gas-solid interface. Two mechanisms have been pointed as governing the sensing properties: the radial modulation of the electron-depleted shell and the electric-field smearing effect. In fact, these heterostructured sensors can be seen as field effect transistors, in which the heterojunction constitutes the gate. The space charge region of the depletion layer is modulated by the adsorption of the target gas. The conductivity channel is then more or less opened or pinched, leading to an amplification of the signal created by the adsorption of the analyte. In the case of a metal-semiconductor junction, spillover effect is driven by the metal and is observed in addition to the depletion modulation by the formed Schottky barrier.

One last interesting point to address is the selectivity toward reducing gases. Several papers reported an improved response toward reducing gases coupled to a decrease toward oxidizing gases. The phenomenon was explained by a deficiency of electron charge carriers which can participate to the surface reaction with the oxidizing gas; because the shell is already fully electron depleted and/or the heterojunction blocks its expansion. However, improved responses to $\mathrm{NO}_{2}$ were demonstrated in some cases such as when core/shell structures made of $\mathrm{Ga}_{2} \mathrm{O}_{3} / \mathrm{ZnO},{ }^{[56 f]} \mathrm{WO}_{3} / \mathrm{ZnO}^{[68]}$ and $\mathrm{CNTs} /$ metal oxides were used as sensing layers. Moreover, it should be noticed that in the latter examples, each isolated core material shows weak intrinsic responses. Therefore, it is not surprising that the addition of more sensitive shell layers improved the sensitivity of the device also toward oxidizing gases. Further studies are still needed to get more insight and for understanding the selectivity to reducing over oxidizing gases of heterostructured gas sensing layer. The reader can refer to the review of Miller et al. for deeper understanding of the sensing mechanism involved in nanostructured oxide heterojunction materials, in general. ${ }^{[102]}$

\section{Optical gas sensors}

Few examples of optical gas sensors using core-shell materials have been reported in the literature. ${ }^{[39 d,}$ ${ }^{82},{ }^{95-96]}{ }^{[966]}$ For instance $\mathrm{ZnO}$ films, ranging from 40 to $220 \mathrm{~nm}$ in thickness, were deposited by ALD onto single mode optical fibers. These structures are sensitive to isopropanol vapors. The propagated light into the optical fiber is reflected at both $\mathrm{ZnO} /$ fiber and surrounding atmosphere/ZnO interfaces due to the change in refractive indexes. The light interference spectrum, created by the two refracted beams, is modified depending on the presence of isopropanol vapor in the surrounding air which changes the refractive index contrast at the gas-solid interface. The modification recorded on the spectrum was used for alcohol vapor detection. ${ }^{[82]} \mathrm{NH}_{3}$ selective sensor was fabricated from microring resonators 
functionalized with mesoporous aluminosilicate. ALD of $\mathrm{Al}_{2} \mathrm{O}_{3}$ was used to introduce acid sites into mesoporous $\mathrm{SiO}_{2}$. The resonance shift recorded in the presence of the target gas permitted a fast, reversible and selective response (compared to $\mathrm{CO}_{2}$ ) to ammonia. ${ }^{[95]}$ Ethanol could be also detected by making use of photoluminescence intensity changes. Electrospun PAN fibers coated with ZnO ALD showed two emission peaks. One is attributed to the near band edge emission (NBE) and the other to deep level emission (DLE). Ethanol is an electron donor promoting an electron transfer upon dissociative adsorption onto ZnO leading to an increase of the NBE and a decrease of the DLE band. Even though the use of photoluminescence changes for gas detection was demonstrated, the recorded responses remained much lower than that of traditional resistive sensors. ${ }^{[39 d]}$ Finally, butterfly wing conformally coated with alumina can be used for the detection of ethanol, acetone and water. A $5 \mathrm{~nm}$-thick $\mathrm{Al}_{2} \mathrm{O}_{3}$ coating improves the response compared to the uncoated material, whereas for thicker coating the optical response vanishes. ${ }^{[96]}$

\section{Conclusions and outlook}

The present article focuses on materials for resistive gas sensor devices in which the sensing material was elaborated using atomic layer deposition, in at least one step of the fabrication. Atomic layer deposition has proven to be well-suited for the elaboration of compact thin films and complex materials, and has been successfully applied to gas sensors since the beginning of the century.

Since in gas sensing an optimum sensitivity is generally observed when the thickness of the semiconductive thin film is in the range of the Debye length, which is usually only of few nanometers thick, atomic layer deposition, allowing a very precise control of the film thickness, is the technique of choice for optimizing the sensitivity of the sensing layer. ${ }^{[11]}$

Atomic layer deposition is also especially suitable for the fabrication of complex nanostructures by coating a semiconductive nanostructured template, so to form a heterojunction. The template can be eventually etched leading to its atomic layer deposition replica. Although a large variety of atomic layer deposition processes for almost all class of materials have been developed in the past two decades, ${ }^{\text {[4] }]}$ only a few have been considered for gas sensing applications. Semiconductive metal oxides are the most studied class of materials for gas sensors, though the materials considered are almost exclusively limited to $\mathrm{ZnO}, \mathrm{SnO}_{2}$ and $\mathrm{TiO}_{2}$ deposited from well-known processes. Few processes are also employed for the deposition of metallic particles such as platinum and palladium for hydrogen sensing. Although a large variety of complex nanostructures and materials combinations can be fabricated using atomic layer deposition, ${ }^{[6 \mathrm{~b}, 6 \mathrm{cc}]}$ most of the studies dedicated to gas sensors focus on the coating of 1D templates such as fibers, nanotubes or nanowires leading to 1D heterostructured metal oxides. Due to the advanced stage of development of atomic layer deposition there are definitely open opportunities for further developing novel structures for gas sensing applications.

$n-n$ and $n-p$ radial heterojunctions based on the combination of two metal oxides displaying different nature and/or density of the charge carries have been fabricated by coating a semiconductive or a sacrificial 1D template, so to form hollow or plain 1D nanostructures displaying a radial modulation of the charge carriers concentration. These heterostructures have been found to display a higher 
sensitivity to the target gas compared to the isolated components and in some of the cases they also exhibit an improved selectivity towards reducing gases.

Finally, area-selective deposition of the material onto a substrate can be achieved by controlling the density of surface active sites (or anchoring sites) toward the nucleation of the atomic layer deposition film, offering additional perspectives to engineering complex nanostructures and to improve the performance of the sensing layers. For example, it was demonstrated that a continuous and pinhole coating was needed in carbon nanostructures/metal oxide $p$-n heterojunctions for an optimized sensor performance, which could be achieved by controlling the density of surface oxygenated species of the carbon substrate. ${ }^{[56 e]}$ Whereas only the decoration of the surface defects along graphene boundaries, leading to 1D platinum nanoparticles chains, was preferred for hydrogen sensing. ${ }^{\text {[9] }}$

All in all, the versatility of atomic layer deposition in respect to the large variety of structures, materials and materials combinations that can be deposited, combined to its simplicity and advanced stage of development makes it the technique of choice for the development of novel materials for gas sensing. 


\section{References}

[1] a) N. Barsan, D. Koziej, U. Weimar, Sensors and Actuators B: Chemical 2007, 121, 18-35; b) G. Korotcenkov, Materials Science and Engineering: B 2007, 139, 1-23; c) M. E. Franke, T. J. Koplin, U. Simon, Small 2006, 2, 301-301.

[2] N. Yamazoe, Sensors and Actuators B: Chemical 1991, 5, 7-19.

[3] a) M. Salmeron, R. Schlögl, Surface Science Reports 2008, 63, 169-199; b) H.-J. Freund, H. Kuhlenbeck, J. Libuda, G. Rupprechter, M. Bäumer, H. Hamann, Topics in Catalysis 2001, 15, 201209; c) G. A. Somorjai, R. L. York, D. Butcher, J. Y. Park, Physical Chemistry Chemical Physics 2007, 9, 3500-3513.

[4] a) V. Miikkulainen, M. Leskela, M. Ritala, R. L. Puurunen, Journal of Applied Physics 2013, 113, 021301; b) R. L. Puurunen, Journal of Applied Physics 2005, 97, 121301-121362; c) S. M. George, Chemical reviews 2010, 110, 111-131.

[5] a) C. S. Hwang, in Atomic Layer Deposition of Nanostructured Materials (Eds.: N. Pinna, M. Knez), Wiley-VCH, 2011, pp. 161-192; b) C. S. Hwang, (Ed.), Atomic Layer Deposition for Semiconductors, Springer US, 2014.

[6] a) M. Knez, Material Matters 2008, 3, 28-30; b) C. Marichy, M. Bechelany, N. Pinna, Advanced Materials 2012, 24, 1017-1032; c) M. Knez, K. Nielsch, L. Niinistö, Advanced Materials 2007, 19, 3425-3438.

[7] A. Rosental, Tarre, A.; Gerst, A.; Uustare, T.; Sammelselg, V., Sensors and Actuators B-Chemical 2001, 77, 297-300.

[8] A. Rosental, A. Tarre, A. Gerst, J. Sundqvist, A. Hårsta, A. Aidla, J. Aarik, V. Sammelselg, T. Uustare, Sensors and Actuators B: Chemical 2003, 93, 552-555.

[9] A. J. Niskanen, A. Varpula, M. Utriainen, G. Natarajan, D. C. Cameron, S. Novikov, V.-M. Airaksinen, J. Sinkkonen, S. Franssila, Sensors and Actuators B: Chemical 2010, 148, 227-232.

[10] G. Choi, L. Satyanarayana, J. Park, Applied Surface Science 2006, 252, 7878-7883.

[11] X. Du, S. M. George, Sensors and Actuators B: Chemical 2008, 135, 152-160.

[12] C. Xu, J. Tamaki, N. Miura, N. Yamazoe, Sensors and Actuators B: Chemical 1991, 3, 147-155.

[13] C. Marichy, N. Donato, M.-G. Willinger, M. Latino, D. Karpinsky, S.-H. Yu, G. Neri, N. Pinna, Advanced Functional Materials 2011, 21, 658-666.

[14] G. Natarajan, D. C. Cameron, Applied Physics A 2009, 95, 621-627.

[15] X. Du, Y. Du, S. M. George, The journal of physical chemistry. A 2008, 112, 9211-9219.

[16] A. Rosental, A. Tarre, A. Gerst, A. Kasikov, J. Lu, M. Ottosson, T. Uustare, Sensors Journal 2013, 13, $1648-1655$.

[17] a) V. A. T. Dam, M. A. Blauw, S. H. Brongersma, M. Crego-Calama, Procedia Engineering 2010, 5, 172-175; b) V. A. T. Dam, M. A. Blauw, S. H. Brongersma, M. Crego-Calama, Procedia Engineering 2011, 25, 112-115; c) M.A. Blauw, V.A.T Dam, M. Crego-Calama, S.H. Brongersma, J. Musschoot, C. Detavernier, Sensors 2011, 1416 - 1419; d) D. Naumenko, V. Snitka, A. Ulcinas, I. Naumenko, K. Grigoras, Theoretical and Experimental Chemistry 2013, 49, 96-102.

[18] a) D.-H. Kim, W.-S. Kim, S. Kim, S.-H. Hong, ACS Applied Materials \& Interfaces 2014, 6, 1181711822; b) Kumar M.K., Tan L. K. , Gosvami N. N., Gao H., j phys chem c 2009, 113, 6381-6389; c) M. K. Kumar, L. K. Tan, N. N. Gosvami, H. Gao, Journal of Applied Physics 2009, 106, 044308.

[19] a) K. B. Jinesh, V. A. T. Dam, J. Swerts, C. de Nooijer, S. van Elshocht, S. H. Brongersma, M. CregoCalama, Sensors and Actuators B: Chemical 2011, 156, 276-282; b) Dam V.A.T., Blauw M.A., Brongersma S.H., van Schaijk R., Key Engineering Materials 2014, 605, 71-74.

[20] T. Hara, T. Ishiguro, Sensors and Actuators B: Chemical 2009, 136, 489-493.

[21] W. Lee, K. Hong, Y. Park, N. H. Kim, Y. Choi, J. Park, Electronics Letters 2005, 41, 475.

[22] S. Mills, M. Lim, B. Lee, V. Misra, ECS J. Solid State Sci. Technol. 2015, 4, S3059-S3061. 
[23] D. H. Kim, W.-S. Kim, S. B. Lee, S.-H. Hong, Sensors and Actuators B: Chemical 2010, 147, 653659.

[24] S. Boyadjiev, V. Georgieva, L. Vergov, Z. Baji, F. Gáber, I. M. Szilágyi, Journal of Physics: Conference Series 2014, 559, 012013.

[25] V. Postica, T. Reimer, E. Lazari, N. Ababii, S. Shishiyanu, S. Railean, V. Kaidas, S. Kaps, O. Lupan, W. Benecke, R. Adelung, in 3rd International Conference on Nanotechnologies and Biomedical Engineering, Vol. 55 (Eds.: V. Sontea, I. Tiginyanu), Springer, New York, 2016, pp. 149-152.

[26] I. Karaduman, M. Demir, D. Esra Yıldız, S. Acar, Physica Scripta 2015, 90, 055802.

[27] I. Karaduman, D. E. Yıldız, M. M. Sincar, S. Acar, Materials Science in Semiconductor Processing 2014, 28, 43-47.

[28] P. Sobas, O. Nilsen, H. Fjellvag, B. G. Svensson, in Silicon Carbide and Related Materials 2009, Pts 1 and 2, Vol. 645-648 (Eds.: A. J. Bauer, P. Friedrichs, M. Krieger, G. Pensl, R. Rupp, T. Seyller), Trans Tech Publications Ltd, Stafa-Zurich, 2010, pp. 531-534.

[29] a) M. Aronniemi, J. Saino, J. Lahtinen, Thin Solid Films 2008, 516, 6110-6115; b) M. Aronniemi, J. Sainio, J. Lahtinen, Applied Surface Science 2007, 253, 9476-9482.

[30] A. Kasikov, A. Gerst, A. Kikas, L. Matisen, A. Saar, A. Tarre, A. Rosental, Open Physics $2009,7$.

[31] R. Parna, A. Tarre, A. Gerst, H. Mandar, A. Niilisk, T. Uustare, A. Rosental, V. Sammelselg, in Advanced Optical Materials, Technologies, and Devices, Vol. 6596 (Eds.: S. Asmontas, J. Gradauskas), Spie-Int Soc Optical Engineering, Bellingham, 2007, pp. 59618-59618.

[32] M. A. Blauw, V. A. T. Dam, M. Crego Calama, S. H. Brongersma, ECS Transactions 2013, 50, 137140.

[33] Y. Hong, C.-H. Kim, J. Shin, K. Y. Kim, J. S. Kim, C. S. Hwang, J.-H. Lee, Sensors and Actuators B: Chemical 2016.

[34] W. F. Lim, H. J. Quah, Q. Lu, Y. Mu, W. A. W. Ismail, B. A. Rahim, S. R. Esa, Y. Y. Kee, C. Z. Zhao, Z. Hassan, K. Y. Cheong, Applied Surface Science 2016, 365, 296-305.

[35] I. Karaduman, Ö. Barin, D. E. Yıldız, S. Acar, Journal of Applied Physics 2015, 118, 174501.

[36] I. Erkens, M. Blauw, M. Verheijen, F. Roozeboom, W. M. M. Kessels, ECS Transactions 2013, 58, 203-214.

[37] H. W. Ra, K. S. Choi, J. H. Kim, Y. B. Hahn, Y. H. Im, Small 2008, 4, 1105-1109.

[38] H. W. Ra, R. Khan, J. T. Kim, B. R. Kang, Y. H. Im, Nanotechnology 2010, 21, 85502.

[39] a) J. Y. Park, S. W. Choi, S. S. Kim, Nanotechnology 2010, 21, 475601; b) S. Cho, D.-H. Kim, B.-S. Lee, J. Jung, W.-R. Yu, S.-H. Hong, S. Lee, Sensors and Actuators B: Chemical 2012, 162, 300-306; c) A. Katoch, S. W. Choi, S. S. Kim, Nanotechnology 2014, 25, 455504; d) R. Viter, A. Abou Chaaya, I. latsunskyi, G. Nowaczyk, K. Kovalevskis, D. Erts, P. Miele, V. Smyntyna, M. Bechelany, Nanotechnology 2015, 26, 105501.

[40] A. Katoch, Z. U. Abideen, J.-H. Kim, S. S. Kim, Sensors and Actuators B: Chemical 2016.

[41] W. S. Kim, B. S. Lee, D. H. Kim, H. C. Kim, W. R. Yu, S. H. Hong, Nanotechnology 2010, 21, 245605.

[42] B.-S. Lee, W.-S. Kim, D.-H. Kim, H.-C. Kim, S.-H. Hong, W.-R. Yu, Smart Materials and Structures 2011, 20, 105019.

[43] J. T. Korhonen, P. Hiekkataipale, J. Malm, M. Karppinen, O. Ikkala, R. H. A. Ras, ACS Nano 2011, 5, 1967-1974.

[44] Y. T. Lim, J. Y. Son, J. S. Rhee, Ceramics International 2013, 39, 887-890.

[45] F. Guder, Y. Yang, A. Menzel, C. Wang, J. Danhof, K. Subannajui, A. Hartel, D. Hiller, R. Kozhummal, N. S. Ramgir, V. Cimalla, U. T. Schwarz, M. Zacharias, Small 2012, 8, 3307-3314.

[46] J. W. Elam, G. Xiong, C. Y. Han, H. H. Wang, J. P. Birrell, U. Welp, J. N. Hryn, M. J. Pellin, T. F. Baumann, J. F. Poco, J. H. Satcher, Journal of Nanomaterials 2006, 2006, 1-5.

[47] W. P. Clavijo, G. M. Atkinson, C. E. Castano, D. Pestov, Journal of Vacuum Science \& Technology B 2016, 34, 022203. 
[48] A. Katoch, J. H. Kim, S. S. Kim, ACS Applied Materials \& Interfaces 2014, 6, 21494-21499.

[49] F. Li, X. Yao, Z. Wang, W. Xing, W. Jin, J. Huang, Y. Wang, Nano letters 2012, 12, 5033-5038.

[50] K. L. Stano, S. Faraji, R. Hodges, O. Yildiz, B. Wells, H. I. Akyildiz, J. Zhao, J. Jur, P. D. Bradford, Small 2016, n/a-n/a.

[51] H. Ma, Y. Wei, J. Wang, X. Lin, W. Wu, Y. Wu, L. Zhang, P. Liu, J. Wang, Q. Li, S. Fan, K. Jiang, Nano Research 2015, 8, 2024-2032.

[52] X. Zhao, W. Shi, H. Mu, H. Xie, F. Liu, Journal of Alloys and Compounds 2016, 659, 60-65.

[53] J. Lee, D. H. Kim, S.-H. Hong, J. Y. Jho, Sensors and Actuators B: Chemical 2011, 160, 1494-1498.

[54] Y. Wang, S. Park, J. T. W. Yeow, A. Langner, F. Müller, Sensors and Actuators B: Chemical 2010, 149, 136-142.

[55] Y. Wang, J. T. W. Yeow, IEEE Sensors Journal 2009, 9, 541-547.

[56] a) S. W. Choi, A. Katoch, G. J. Sun, J. H. Kim, S. H. Kim, S. S. Kim, ACS Appl Mater Interfaces 2014, 6, 8281-8287; b) A. Katoch, S.-W. Choi, G.-J. Sun, S. S. Kim, Journal of Materials Chemistry A 2013, 1, 13588; c) J. H. Kim, A. Katoch, S. H. Kim, S. S. Kim, ACS Applied Materials \& Interfaces 2015, 7, 15351-15358; d) J.-H. Kim, A. Katoch, S. S. Kim, Sensors and Actuators B: Chemical 2016, 222, 249-256; e) C. Marichy, P. A. Russo, M. Latino, J.-P. Tessonnier, M.-G. Willinger, N. Donato, G. Neri, N. Pinna, The Journal of Physical Chemistry C 2013, 19729-19739; f) C. Jin, S. Park, H. Kim, C. Lee, Sensors and Actuators B: Chemical 2012, 161, 223-228.

[57] a) M. G. Willinger, G. Neri, E. Rauwel, A. Bonavita, G. Micali, N. Pinna, Nano letters 2008, 8, 4201-4204; b) M. G. Willinger, G. Neri, A. Bonavita, G. Micali, E. Rauwel, T. Herntrich, N. Pinna, Physical Chemistry Chemical Physics 2009, 11, 3615-3622.

[58] S. Santangelo, G. Messina, G. Faggio, M. G. Willinger, N. Pinna, A. Donato, A. Arena, N. Donato, G. Neri, Diamond and Related Materials 2010, 19, 590-594.

[59] U. Singh, H. A. Lee, Y.-C. Byun, A. Kumar, S. Seal, H. Kim, H. J. Cho, Procedia Engineering 2011, 25, 1669-1672.

[60] H. Mu, Z. Zhang, X. Zhao, F. Liu, K. Wang, H. Xie, Applied Physics Letters 2014, 105, 033107.

[61] H. Xie, K. Wang, Z. Zhang, X. Zhao, F. Liu, H. Mu, rsc advances 2015, 5, 28030-28037.

[62] S. W. Choi, J. Y. Park, S. S. Kim, Nanotechnology 2009, 20, 465603.

[63] J. Y. Park, S.-W. Choi, S. S. Kim, Journal of Physics D: Applied Physics 2011, 44, 205403.

[64] H. Kim, C. Jin, S. Park, C. Lee, Materials Research Bulletin 2012, 47, 2708-2712.

[65] S. Park, S. An, Y. Mun, C. Lee, ACS Applied Materials \& Interfaces 2013, 5, 4285-4292.

[66] S. Park, S. An, H. Ko, S. Lee, H. W. Kim, C. Lee, Applied Physics A 2014, 115, 1223-1229.

[67] J. Y. Park, S.-W. Choi, J.-W. Lee, C. Lee, S. S. Kim, Journal of the American Ceramic Society 2009, 92, 2551-2554.

[68] S. An, S. Park, H. Ko, C. Lee, Applied Physics A 2012, 108, 53-58.

[69] a) V. Dobrokhotov, L. Oakes, D. Sowell, A. Larin, J. Hall, A. Barzilov, A. Kengne, P. Bakharev, G. Corti, T. Cantrell, T. Prakash, J. Williams, L. Bergman, J. Huso, D. Mcllroy, Sensors (Basel) 2012, 12, 5608-5622; b) V. Dobrokhotov, L. Oakes, D. Sowell, A. Larin, J. Hall, A. Kengne, P. Bakharev, G. Corti, T. Cantrell, T. Prakash, J. Williams, D. N. Mcllroy, Sensors and Actuators B: Chemical 2012, 168, 138-148; c) V. Dobrokhotov, L. Oakes, D. Sowell, A. Larin, J. Hall, A. Kengne, P. Bakharev, G. Corti, T. Cantrell, T. Prakash, J. Williams, D. N. Mcllroy, Journal of Applied Physics 2012, 111, 044311.

[70] S. Park, G. J. Sun, C. Lee, J. Ceram. Process. Res. 2015, 16, 367-371.

[71] S. Park, H. Ko, S. Kim, C. Lee, Journal of the Korean Physical Society 2014, 65, 1585-1589.

[72] C. Jin, H. Kim, S. Park, S.-W. Choi, S. S. Kim, C. Lee, Surface and Interface Analysis 2012, 44, 15341537.

[73] A. Katoch, S. W. Choi, G. J. Sun, H. W. Kim, S. S. Kim, Nanotechnology 2014, 25, 175501.

[74] S. Park, S. Kim, H. Ko, C. Lee, Journal of Electroceramics 2014, 33, 75-81. 
[75] S. Park, S. An, H. Ko, C. Jin, C. Lee, Ceramics International 2013, 39, 3539-3545.

[76] S. Park, H. Ko, S. Kim, C. Lee, ACS Applied Materials \& Interfaces 2014, 6, 9595-9600.

[77] S. Park, H. Kim, C. Jin, C. Lee, Journal of Nanoscience and Nanotechnology 2013, 13, 3427-3432.

[78] S. Park, S. Park, S. Lee, H. W. Kim, C. Lee, Sensors and Actuators B: Chemical 2014, 202, 840-845.

[79] S. Park, H. Ko, S. Lee, H. Kim, C. Lee, Thin Solid Films 2014, 570, 298-302.

[80] A. Mirzaei, S. Park, H. Kheel, G.-J. Sun, S. Lee, C. Lee, Ceramics International 2016, 42, 61876197.

[81] J. H. Kim, S. S. Kim, ACS Appl Mater Interfaces 2015, 7, 17199-17208.

[82] M. Śmietana, J. Grochowski, M. Myśliwiec, Ł. Wachnicki, M. Godlewski, B. S. Witkowski, Procedia Engineering 2012, 47, 1081-1084.

[83] C. Wongchoosuk, K. Subannajui, C. Wang, Y. Yang, F. Guder, T. Kerdcharoen, V. Cimalla, M. Zacharias, rsc advances 2014, 4, 35084-35088.

[84] Y.-C. Liang, W.-K. Liao, S.-L. Liu, rsc advances 2014, 4, 50866-50872.

[85] C. Marichy, N. Donato, M. Latino, M. G. Willinger, J. P. Tessonnier, G. Neri, N. Pinna, Nanotechnology 2015, 26, 024004.

[86] M. Mattmann, C. Roman, T. Helbling, D. Bechstein, L. Durrer, R. Pohle, M. Fleischer, C. Hierold, Nanotechnology 2010, 21, 185501.

[87] Y.-G. Jang, W.-S. Kim, D.-H. Kim, S.-H. Hong, Journal of Materials Research 2011, 26, 2322-2327.

[88] G. Neri, S. G. Leonardi, N. Donato, C. Marichy, J. P. Tessonnier, M. G. Willinger, K.-H. Lee, N. Pinna, Procedia Engineering 2012, 47, 1259-1262.

[89] M. T. Humayun, R. Divan, L. Stan, A. Gupta, D. Rosenmann, L. Gundel, P. A. Solomon, I. Paprotny, Journal of Vacuum Science \& Technology B 2015, 33, 06FF01.

[90] D. J. Lee, K. Heo, H. Lee, J. H. Jin, H. Chang, M. Park, H. B. Lee, H. Kim, B. Y. Lee, Nanoscale research letters 2015, 10, 18.

[91] Y.-H. Lin, Y.-C. Hsueh, P.-S. Lee, C.-C. Wang, J.-R. Chen, J.-M. Wu, T.-P. Perng, H. C. Shih, Journal of the Electrochemical Society 2010, 157, K206.

[92] Y.-H. Lin, Y.-C. Hsueh, P.-S. Lee, C.-C. Wang, J. M. Wu, T.-P. Perng, H. C. Shih, Journal of Materials Chemistry 2011, 21, 10552.

[93] K. Kim, H. B. Lee, R. W. Johnson, J. T. Tanskanen, N. Liu, M. G. Kim, C. Pang, C. Ahn, S. F. Bent, Z. Bao, Nature communications 2014, 5, 4781.

[94] M. T. Taschuk, K. D. Harris, D. P. Smetaniuk, M. J. Brett, Sensors and Actuators B: Chemical 2012, 162, 1-6.

[95] N. A. Yebo, S. P. Sree, E. Levrau, C. Detavernier, Z. Hens, J. A. Martens, R. Baets, Optics express 2012, 20, 11855-11862.

[96] a) K. Kertész, G. Piszter, Z. Baji, E. Jakab, Z. Bálint, Z. Vértesy, L. P. Biró, Chemical Sensors 2014, 4; b) G. Piszter, K. Kertész, Z. Vértesy, Z. Bálint, L. P. Biró, Optics express 2014, 22, 22649-22660.

[97] C. Marichy, A. Pucci, M.-G. Willinger, N. Pinna, in Atomic Layer Deposition of Nanostructured Materials (Eds.: N. Pinna, M. Knez), Wiley-VCH, 2011, pp. 327-343.

[98] A. T. Iancu, M. Logar, J. Park, F. B. Prinz, ACS Applied Materials \& Interfaces 2015, 7, 5134-5140.

[99] a) A. Kolmakov, X. Chen, M. Moskovits, Journal of Nanoscience and Nanotechnology 2008, 8, 111-121; b) F.-L. Meng, Z. Guo, X.-J. Huang, TrAC Trends in Analytical Chemistry 2015, 68, 37-47; c) N. L. W. Septiani, B. Yuliarto, Journal of The Electrochemical Society 2016, 163, B97-B106.

[100] C. Marichy, N. Pinna, Coordination Chemistry Reviews 2013, 257, 3232-3253.

[101] V. Dobrokhotov, A. Larin, D. Sowell, Sensors (Basel) 2013, 13, 9016-9028.

[102] D. R. Miller, S. A. Akbar, P. A. Morris, Sensors and Actuators B: Chemical 2014, 204, 250-272. 
